\title{
TU/e EN⿴HONE

\section{Optimization of the output and efficiency of a high power cascaded arc hydrogen plasma source}

\section{Citation for published version (APA):}

Vijvers, W. A. J., van Gils, K., Goedheer, W. J., Meiden, van der, H. J., Schram, D. C., Veremiyenko, V. P., Westerhout, J., Lopes Cardozo, N. J., \& Rooij, van, G. J. (2008). Optimization of the output and efficiency of a high power cascaded arc hydrogen plasma source. Physics of Plasmas, 15(9), 093507. https://doi.org/10.1063/1.2979703

DOI:

$10.1063 / 1.2979703$

Document status and date:

Published: 01/01/2008

\section{Document Version:}

Publisher's PDF, also known as Version of Record (includes final page, issue and volume numbers)

\section{Please check the document version of this publication:}

- A submitted manuscript is the version of the article upon submission and before peer-review. There can be important differences between the submitted version and the official published version of record. People interested in the research are advised to contact the author for the final version of the publication, or visit the $\mathrm{DOI}$ to the publisher's website.

- The final author version and the galley proof are versions of the publication after peer review.

- The final published version features the final layout of the paper including the volume, issue and page numbers.

Link to publication

\section{General rights}

Copyright and moral rights for the publications made accessible in the public portal are retained by the authors and/or other copyright owners and it is a condition of accessing publications that users recognise and abide by the legal requirements associated with these rights.

- Users may download and print one copy of any publication from the public portal for the purpose of private study or research.

- You may not further distribute the material or use it for any profit-making activity or commercial gain

- You may freely distribute the URL identifying the publication in the public portal.

If the publication is distributed under the terms of Article 25fa of the Dutch Copyright Act, indicated by the "Taverne" license above, please follow below link for the End User Agreement:

www.tue.nl/taverne

Take down policy

If you believe that this document breaches copyright please contact us at:

openaccess@tue.nl

providing details and we will investigate your claim. 


\title{
Optimization of the output and efficiency of a high power cascaded arc hydrogen plasma source
}

\author{
W. A. J. Vijvers, ${ }^{1}$ C. A. J. van Gils, ${ }^{1}$ W. J. Goedheer, ${ }^{1}$ H. J. van der Meiden, ${ }^{1}$ \\ D. C. Schram, ${ }^{2}$ V. P. Veremiyenko, ${ }^{1}$ J. Westerhout, ${ }^{1}$ N. J. Lopes Cardozo, ${ }^{1}$ \\ and G. J. van Rooij ${ }^{i}$ a) \\ ${ }_{1}^{1}$ FOM-Institute for Plasma Physics Rijnhuizen, Association EURATOM-FOM, Trilateral Euregio Cluster, \\ P.O. Box 1207, 3430 BE Nieuwegein, The Netherlands \\ ${ }^{2}$ Department of Applied Physics, Eindhoven University of Technology, P.O. Box 513, \\ 5600 MB Eindhoven, The Netherlands
}

(Received 8 August 2008; accepted 19 August 2008; published online 17 September 2008)

\begin{abstract}
The operation of a cascaded arc hydrogen plasma source was experimentally investigated to provide an empirical basis for the scaling of this source to higher plasma fluxes and efficiencies. The flux and efficiency were determined as a function of the input power, discharge channel diameter, and hydrogen gas flow rate. Measurements of the pressure in the arc channel show that the flow is well described by Poiseuille flow and that the effective heavy particle temperature is approximately $0.8 \mathrm{eV}$. Interpretation of the measured $I-V$ data in terms of a one-parameter model shows that the plasma production is proportional to the input power, to the square root of the hydrogen flow rate, and is independent of the channel diameter. The observed scaling shows that the dominant power loss mechanism inside the arc channel is one that scales with the effective volume of the plasma in the discharge channel. Measurements on the plasma output with Thomson scattering confirm the linear dependence of the plasma production on the input power. Extrapolation of these results shows that (without a magnetic field) an improvement in the plasma production by a factor of 10 over where it was in van Rooij et al. [Appl. Phys. Lett. 90, 121501 (2007)] should be possible. () 2008 American Institute of Physics. [DOI: 10.1063/1.2979703]
\end{abstract}

\section{INTRODUCTION}

\section{A. Motivation}

The cascaded arc plasma source is a suitable choice for applications that require high fluxes of ions, photons or radicals at low plasma temperatures $(0.1$ to $10 \mathrm{eV}) .{ }^{1-4}$ In our plasma surface interaction experiment, the cascaded arc is combined with a strong axial magnetic field $(\leqslant 1.6 \mathrm{~T})$ to create an intense magnetized hydrogen plasma beam $\left(\sim 10 \mathrm{MW} / \mathrm{m}^{2}\right.$ to the target). In this paper we determine scaling laws for the operation (i.e., current-voltage characteristics) and plasma output (gas efficiency), of the cascaded arc operating on hydrogen. The main variables are the input power $\left(P_{\text {in }}\right)$, the gas flow rate $(\Phi)$, and the diameter of the discharge channel $(d$ or $\oslash)$.

The motivation for our work originates from issues related to plasma wall interaction in future fusion reactors like ITER. ${ }^{5}$ In ITER, the so-called divertor functions as the exhaust for the fusion product ${ }^{4} \mathrm{He}$, impurities, and part of the fusion power. The steady state heat flux density to high flux areas of the ITER wall is expected to reach $\sim 10 \mathrm{MW} \mathrm{m}^{-2}$. It will be delivered by an extreme particle flux density of $10^{24}$ ions $\mathrm{m}^{-2} \mathrm{~s}^{-1}$ at a temperature of $1-10 \mathrm{eV}$. In such conditions, fast erosion and high retention rates of the tritium fuel may limit prolonged operation. ${ }^{6}$ Knowledge about the complex system of plasma-surface interactions (PSIs) in these conditions is incomplete, because the combination of

${ }^{a)}$ Electronic mail: G.J.vanRooij@ rijnhuizen.nl.
ITER-like flux-densities, electron temperatures and fluences is not attained in current fusion reactors or laboratory experiments.

The FOM Institute for Plasma Physics Rijnhuizen is building the linear plasma generator Magnum-PSI (MAgnetized plasma Generator and NUmerical Modelling) ${ }^{7}$ to study the high flux, low temperature and strong magnetic field regime of PSI. The specifications of Magnum-PSI are: $\oslash 10 \mathrm{~cm}$ plasma beam diameter, steady-state flux densities up to $10^{24}$ ions $\mathrm{m}^{-2} \mathrm{~s}^{-1}$, electron temperatures of $1-7 \mathrm{eV}$, variable magnetic field of up to $3 \mathrm{~T}$, and background pressures of $\sim 1 \mathrm{~Pa}$. Assuming a parabolic flux profile, these requirements correspond to a total ion flux of $\Gamma_{i}=4$ $\times 10^{21}$ ions s$^{-1}$. A high efficiency, high flux cascaded arc hydrogen plasma source is the key component of this device. High pressure hydrogen plasma sources such as the cascaded arc usually operate at low gas efficiency due to conductive and particle losses to the source walls and anomalously fast volume recombination rates. ${ }^{8,9}$ The aim of this work is to improve the output and efficiency of the cascaded arc enough to satisfy the requirements for Magnum-PSI.

In the past, we have applied a cascaded arc according to the design of Kroesen et al. ${ }^{10}$ on our linear plasma generator Pilot-PSI, the forerunner of Magnum-PSI. This yielded unprecedented plasma fluxes and densities by virtue of a synergetic action of high magnetic fields and an optimized nozzle geometry. ${ }^{11}$ However, the total plasma flux was still an order of magnitude lower than what is required for Magnum-PSI. In this paper, we investigate how the plasma production can be improved by a factor of 10 over what the 
flux is in the operational conditions of Ref. $11(d=4 \mathrm{~mm}$, $P_{\text {in }}=12 \mathrm{~kW}, \Phi=2.5 \mathrm{slm}$ ), without employing the nozzlefield effect. This gives a flux requirement of $\Gamma_{\mathrm{H}^{+}}^{\text {out }}$ $=6 \cdot 10^{20} \mathrm{~s}^{-1}$. It is investigated how the channel diameter, input power and hydrogen flow rate determine the plasma production. An empirical model is developed on the basis of $I-V$ measurements for an extrapolation of the plasma fluxes to those required for Magnum-PSI. Thomson scattering and optical emission measurements are employed to check the predictions made by the empirical model and to estimate absolute values of the ion flux and gas efficiency.

\section{B. Background from the literature}

It is known from the literature that in hydrogen and nitrogen arcs, the discharge current is concentrated in the center of the channel, where the electron temperature and ionization degree is high. ${ }^{12,13}$ This current conduit widens as the input power is increased. As a result, the $I-V$ characteristic flattens or even develops a negative slope. The power deposition into the arc depends on the plasma resistance. The conductivity $(\sigma)$ in the hot core depends on the electron temperature $\left(T_{e}\right)$ according to the Spitzer relation ${ }^{14}$

$$
\sigma=\frac{2 \times 10^{4} \hat{T}_{e}^{3 / 2}}{\ln \Lambda},
$$

where $\hat{T}_{e}$ is the electron temperature in $\mathrm{eV}$. The conductivity is strongly dependent on $T_{e}$. The dependence on $n_{e}$ is weak. The electron temperature inside the current conduit can be calculated from a charged particle balance that equates the production of new electrons and ions to the convective loss of charged particles from the source via sonic outflow. In Ref. 15, this is shown to lead to an electron temperature of

$$
\hat{T}_{e} \approx \frac{\hat{E}_{\mathrm{ion}}}{\ln (10 p L \sqrt{A})-\ln \left(\hat{T}_{h}\right)},
$$

where $\hat{E}_{\text {ion }}$ is the ionization energy in eV $(13.6 \mathrm{eV}$ for hydrogen), $p$ is the pressure in the discharge channel, $L$ the length of the channel, $A$ is the atomic mass (1 a.m.u. for atomic hydrogen) and $\hat{T}_{h}$ is the temperature of the heavy particles (i.e., $\mathrm{H}$ and $\mathrm{H}^{+}$).

\section{Outline}

A series of sources with discharge channel diameters of 4-7 mm was tested on Pilot-PSI. Details of the setup and diagnostics are given in Sec. II. All experimental results are given in Sec. III. To check if the flow in the discharge channel is laminar and to be able to estimate the heavy particle temperature to be used in Eq. (2), the pressure at the gas inlet was measured for all sources as a function of $\Phi$ and $P_{\text {in }}$. As described in Sec. IV B, the conductance of the arc channel provides a measure of the plasma production. To determine how the plasma production scales with the operating parameters, the discharge voltage was measured as a function of the discharge current between 60 and 300 A at different hydrogen flow rates and channel diameters. The voltage was also measured in a scan of the gas flow rate between 0.5 and
10 standard liters per minute $\left(\operatorname{slm}=4.5 \times 10^{20}\right.$ particles per second) at a discharge current of $100 \mathrm{~A}$ to investigate the influence of the pressure on the source operation. For the same set of operating conditions, the plasma output (electron density and temperature profiles) was measured with Thomson scattering (TS). For one set of operational parameters, the convective plasma velocity was measured with high resolution optical emission spectroscopy (OES).

In Sec. IV, first the pressure measurements are analyzed in terms of Poiseuille flow and an estimate of the heavy particle temperature is made. Assuming that the central temperature in the current conduit is dependent on $p$ [via Eq. (2)], but not on $P_{\text {in }}$, we then define a model with just one parameter: the effective radius of the current conduit $r_{\text {eff }}$. Using this model, we estimate from the $I-V$ measurements the plasma production and determine how it scales as a function of $P_{\text {in }}, d$, and $\Phi$. The ionization degree inside the current conduit (the only free parameter in the model at this point) is calibrated by comparing with the measured plasma flux from the combined TS and OES measurements.

From the results in Ref. 11, it is known that the magnetic field has a strong effect on the operation of our cascaded arc source and can have a very positive effect on the plasma production. No magnetic fields were applied in the voltage measurements in order to focus on the source operation and eliminate nozzle-field effects. The TS and OES measurements, however, required a magnetic field because otherwise the plasma recombination length scale would have been smaller than the distance between the arc and the TS measurement $(4 \mathrm{~cm})$. Only fields smaller than $0.4 \mathrm{~T}$ were used in order to minimize the extra power input in the nozzle region. In Sec. V, we estimate the extent to which the source operation is determined by the field. Using the scaling found from the $I-V$ measurements, we finally extrapolate the measured plasma fluxes to those required for Magnum-PSI, considering the power load on the source walls. We give a short summary and conclusions in Sec. VI.

\section{EXPERIMENTAL SETUP}

\section{A. Cascaded arc plasma source}

A schematic of the cascaded arc is shown in Fig. 1. It consists of a cascade of $5 \mathrm{~mm}$ thick copper plates that are electrically insulated from each other. Vacuum sealing and electrical insulation is accomplished by $1 \mathrm{~mm}$ thick heat resistant boron-nitride $(\mathrm{BN})$ spacers inside O-rings, mechanically stabilized by polyvinylchloride spacers outside the O-rings. The central holes of the plates together form the discharge channel. The channel diameter was varied between 4 and $7 \mathrm{~mm}$ in the present experiments. Three cathodes, made of thoriated tungsten, are inserted in a gas chamber in front of the discharge channel. The cathode tips, heated to $\sim 3000 \mathrm{~K}$ by ion impact, emit electrons thermionically (i.e., by the thermal vibrational energy of the electrons overcoming the restraining potential). The $2 \mathrm{~mm}$ thick cathode tips are inserted at an angle of $45^{\circ}$ into the cathode chamber. They are each individually connected to one of the three power supplies. The discharge gas is fed into the arc via the same chamber. The pressure in this region is typically 


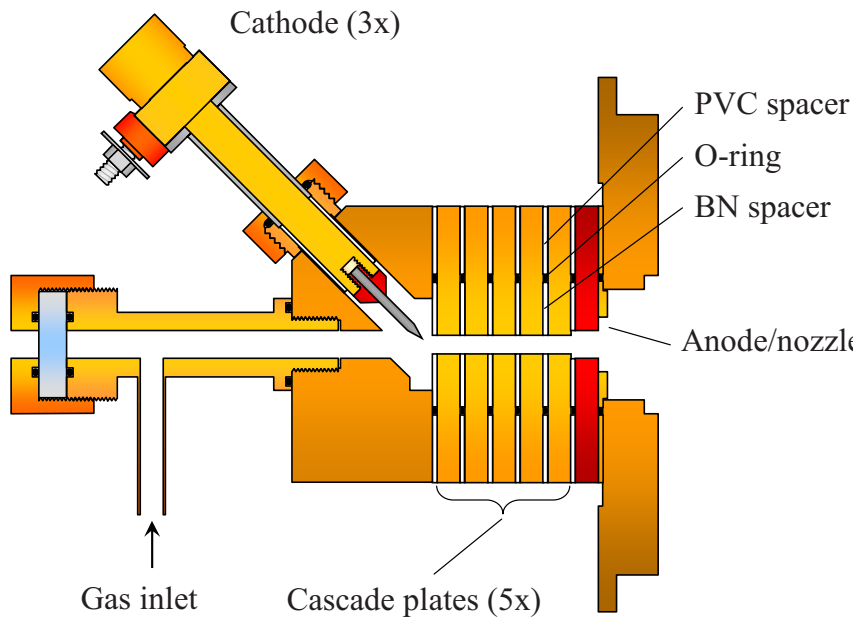

FIG. 1. (Color online) Schematic of the configuration of the cascaded arc plasma source with three cathodes. Five cascade plates are used. $\mathrm{H}_{2}$ gas is fed into the source at gas flow rates of $0.2-10 \mathrm{slm}$. A current of $80-300 \mathrm{~A}$ ionizes the gas. The water-cooled segmented wall stabilizes the discharge. The discharge channel is $4-7 \mathrm{~mm}$ wide. The nozzle/anode plate has a diameter of $6-8.5 \mathrm{~mm}$.

$10^{3}-10^{4} \mathrm{~Pa}$ during operation and depends on the channel diameter, gas flow rate and discharge current. The last plate of the cascade serves as the nozzle as well as the anode. It is made of a $75 \%-25 \%$ tungsten-copper composite (Sparkal X by Plansee) and electrically connected via the endplate to earth by a copper spacer. The inner diameter of the anode is increased with respect to the discharge channel. The sizes are listed in Table I. Considering the thickness of the plates and spacers and the alignment of the cathodes, the length of the discharge channel is $33 \mathrm{~mm}$ (measured from the tip of the cathode to the front of the anode). All components are watercooled by approximately $\sim 5 \mathrm{l} / \mathrm{min}$ of water at $10 \mathrm{bar}$.

\section{B. Pilot-PSI and experimental procedures}

The cascaded arc sources were tested in the linear plasma generator Pilot-PSI (see Fig. 2). The device consists of a $1.2 \mathrm{~m}$ long, $0.4 \mathrm{~m}$ diameter vacuum vessel that is placed inside five coils. The maximum magnetic field strength is $1.6 \mathrm{~T}$ at the center of the vessel, but for the present research only fields up to $0.4 \mathrm{~T}$ were used. The cascaded arc plasma source is placed on the magnetic field axis. Two root blowers $\left(2 \times 4000 \mathrm{~m}^{3} / \mathrm{h}\right.$ pumping speed $)$ operate in parallel to maintain the vessel pressure at $1-15 \mathrm{~Pa}$ during operation (de-

TABLE I. Details of the four source configurations that were investigated. Listed are the discharge channel diameter $d$ and the inner diameter of the anode plate $d_{\mathrm{an}}$. From the tip of the cathode to the beginning of the anode plate, all sources are $33 \mathrm{~mm}$ long.

\begin{tabular}{ccl}
\hline \hline Configuration & $d(\mathrm{~mm})$ & $d_{\text {an }}(\mathrm{mm})$ \\
\hline I & 4 & 6 \\
II & 5 & 7.5 \\
III & 6 & 8 \\
IV & 7 & 8.5 \\
\hline
\end{tabular}

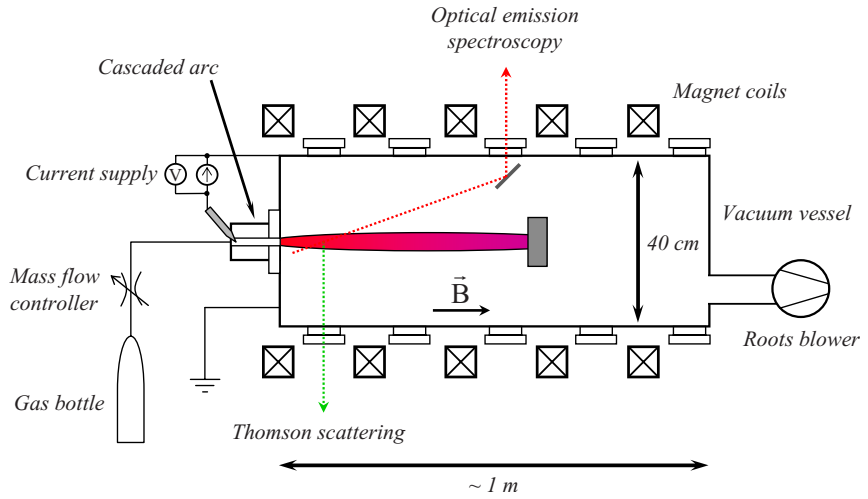

FIG. 2. (Color online) Overview of Pilot-PSI with source, vacuum vessel, pumps, coils and target indicated. A cascaded arc exhausts hydrogen plasma into the vacuum vessel. Five coils produce a magnetic field of up to $1.6 \mathrm{~T}$ in the center of the vessel to confine the plasma. TS at $4 \mathrm{~cm}$ from the source exit measures $n_{e}$ and $T_{e}$ profiles. OES at a $15^{\circ}$ angle to the experiment axis measures the axial velocity of the plasma.

pending on the inlet gas flow). The plasma is deposited on a water-cooled target at $56 \mathrm{~cm}$ downstream. The target is at floating potential.

Discharges were started on argon at a flow rate of $2 \mathrm{slm}$ by a high voltage pulse $(700 \mathrm{~V})$ and subsequently stabilized on $80 \mathrm{~A}$ total current by three DC current supplies (Regatron TopCon Quadro TC.P.32.400.400.S, $32 \mathrm{~kW}, 100 \mathrm{~A}, 400 \mathrm{~V})$. After a few minutes, the gas composition was gradually changed from $100 \%$ argon to $100 \%$ hydrogen. Subsequently, the operational settings were adjusted to the desired values: a gas flow rate between 0.2 and $10 \mathrm{slm}$ and a discharge current between 60 and $300 \mathrm{~A}$. This was followed by a magnetic field pulse of $0.2-0.4 \mathrm{~T}$ for typically $30 \mathrm{~s}$ to allow for TS and OES measurements.

\section{Diagnostics}

The cathode voltages and currents delivered by the power supplies were recorded with a PC-based data acquisition (DAQ) system operating at about $3 \mathrm{~Hz}$ to yield $I-V$ characteristics and input power. The same system recorded the reading of a pressure gauge installed at the gas inlet of the cascaded arc (membrane gauge PRAD D005.S70.C210, Baumer sensopress, 1-1000 mbar).

Electron density $\left(n_{e}\right)$ and temperature $\left(T_{e}\right)$ profiles were measured with TS at about $4 \mathrm{~cm}$ from the source exit (Fig. 2 ). The frequency doubled output of a Nd:YAG laser $(532 \mathrm{~nm}, 3 \mathrm{~ns}, 0.5 \mathrm{~J}, 10 \mathrm{~Hz}$ ) was passed vertically through the vessel and focused in the center of the plasma. Scattered light was collected at a scattering angle of $90^{\circ}$ and relayed to a spectrometer with a bundle of 50 fibers. For each measurement, light from 30 laser pulses was spectrally and spatially resolved in a $1 \mathrm{~m}$ Littrow spectrometer, amplified by a Generation-III intensifier and recorded with an intensified charge-coupled device (CCD) camera. Electron densities were absolutely calibrated by Rayleigh scattering on argon. The data were corrected for stray light and CCD noise and fitted with a series of Gaussian distributions to yield spatial 
$n_{e}$ and $T_{e}$ profiles. Details about the Thomson scattering setup at Pilot-PSI, including an analysis of the observational errors, are described in Ref. 16.

The axial velocity of the plasma was determined with high resolution OES on the Balmer- $\beta\left(\mathrm{H}_{\beta}\right)$ line. Light emitted from the $\mathrm{H}_{\beta}$ line was collected at a $15^{\circ}$ angle from the axis of the experiment (Fig. 2). The light was relayed to a $2.25 \mathrm{~m}$ Littrow spectrometer with a fiber array, spatially and spectrally resolved, and recorded with a CCD camera. The Doppler shift of the center of the line gives the axial velocity. We note that the measured Doppler shift represents an average over the full width of the plasma beam and over several centimeters in the axial direction. Furthermore, as the emissivity profile of the plasma beam in these conditions is hollow, ${ }^{17}$ the slower edges of the beam contribute most to the measured signal.

\section{Data analysis and definitions}

The voltage and pressure data that were recorded at $3 \mathrm{~Hz}$ with the DAQ system were averaged over typically 10 seconds. The cathode voltage $\left(V_{\text {cath }}\right)$ is the average voltage of the three cathodes. The source current $\left(I_{\text {arc }}\right)$ is the sum of the individual cathode currents. The input power was calculated by multiplying the source voltage with the source current:

$$
P_{\text {in }}=I_{\text {arc }} V_{\text {cath }} .
$$

We note that the differences in current between the three cathodes were always very small $(<1 \%)$.

In order to average out scatter in the measured $n_{e}$ and $T_{e}$ and to symmetrize the profiles for cylindrical integration, we fitted all profiles with a profile of the form

$$
y=A\left[1-\frac{1}{1+e^{\left(x-x_{1}\right) / d x}}-\frac{1}{1+e^{-\left(x-x_{2}\right) / d x}}\right] .
$$

$d x$ is a measure of the slope of the side of the profile. An example of a $n_{e}$ and $T_{e}$ profile measured with TS and the corresponding fit is shown in Fig. 3. The shape of the measured profiles are accurately reproduced by the fit. Equation (4) can be used to fit a variety of peaked profile shapes. At the edges of the beam the signal-to-noise ratio is too low to accurately determine $n_{e}$ and $T_{e}$. Here, the fits are used to extrapolate the profile out to a radius of $15 \mathrm{~mm}$, where the electron density is in all cases negligible. The peak $n_{e}$ and $T_{e}$ values presented in this paper are the maxima of the fitted curves. The plasma profile width refers to the full width at half maximum of the fitted $n_{e}$ profile. The fitted curves were integrated radially according to

$$
N=\int_{0}^{15 \mathrm{~mm}} n_{e, f i t}\left(r^{\prime}\right) 2 \pi r^{\prime} d r^{\prime}
$$

where $r^{\prime}=r-r_{0}$ and $r_{0}=\left(x_{1}+x_{2}\right) / 2$ is the center of the $n_{e}$ profile.

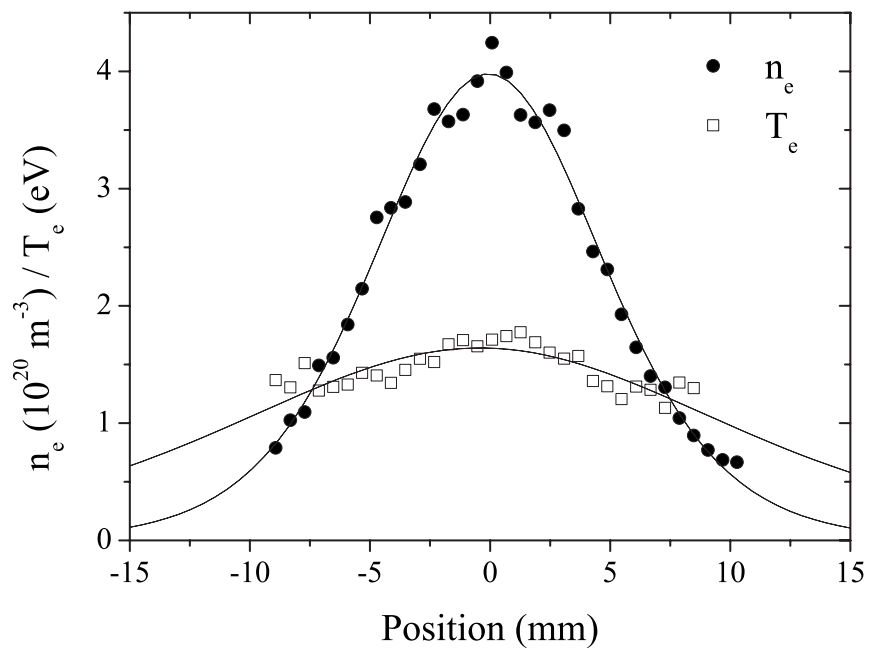

FIG. 3. Example of a typical fit of the electron density and temperature profiles. The source diameter was $5 \mathrm{~mm}$, the current $185 \mathrm{~A}$, the $\mathrm{H}_{2}$ gas flow rate $3.5 \mathrm{slm}$, and the magnetic field $0.2 \mathrm{~T}$. The shape of the measured profiles are accurately reproduced by the fit. Figure 4 can be used to fit a variety of different peaked profile shapes.

\section{EXPERIMENTAL RESULTS}

\section{A. Pressure measurements}

The pressure at the gas inlet of the cascaded arc was measured as a function of the inlet $\mathrm{H}_{2}$ flow between 0.2 and $10 \mathrm{slm}$ for channel diameters between 4 and $7 \mathrm{~mm}$. The discharge current was always $100 \mathrm{~A}$ and the magnetic field was $0.4 \mathrm{~T}$. Figure 4 shows the results. In the investigated range of gas fluxes and diameters, the inlet pressure varies between 20 and 200 mbar. It increases nonlinearly with increasing gas flux and decreases with increasing channel diameter.

The pressure was also measured as a function of the input power. These results are shown in Fig. 5 for channel diameters between 4 and $6 \mathrm{~mm}$, a gas flow rate of $3.5 \mathrm{slm}$, and a magnetic field of $0.2 \mathrm{~T}$. The data show a linear in-

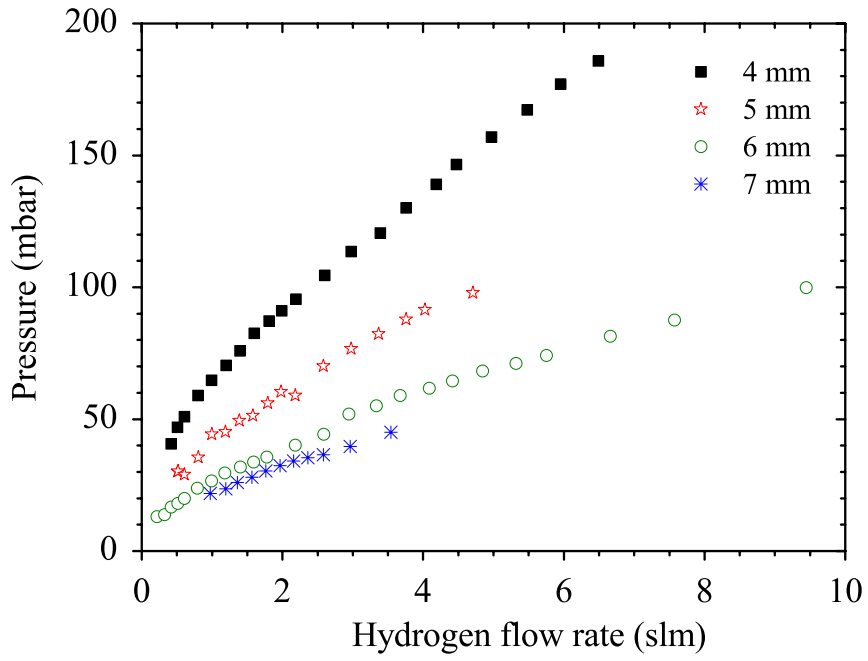

FIG. 4. (Color online) Pressure in the cathode chamber as a function of the hydrogen flow rate for channel diameters between 4 and $7 \mathrm{~mm}$. For all measurements, the discharge current was $100 \mathrm{~A}$ and the magnetic field $0.4 \mathrm{~T}$. The pressure is seen to increase with gas flow rate and decrease with the channel diameter. 


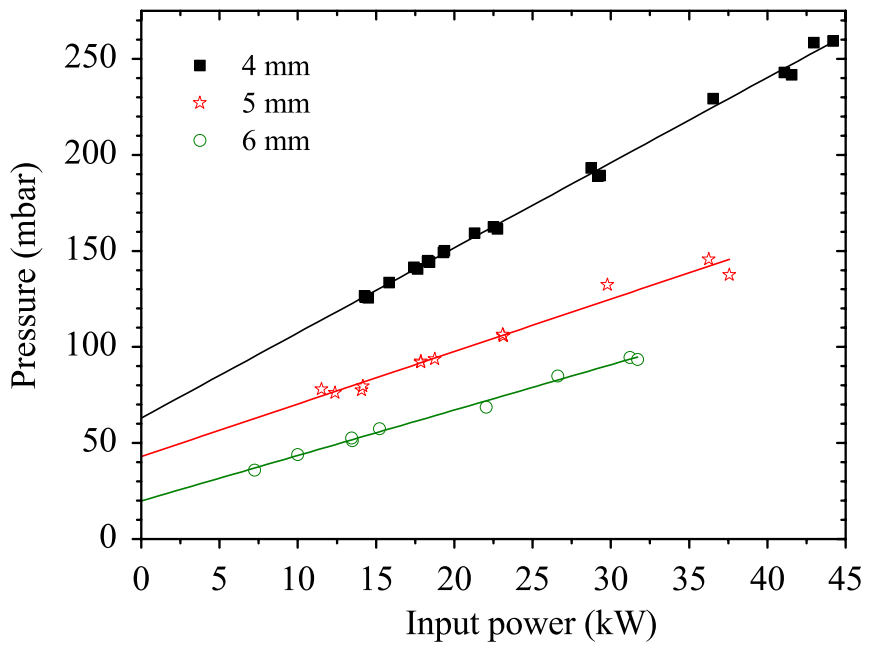

FIG. 5. (Color online) Pressure in the cathode chamber as a function of the total input power for channel diameters between 4 and $6 \mathrm{~mm}$. For all measurements, the gas flow rate was $3.5 \mathrm{slm}$ and the magnetic field $0.2 \mathrm{~T}$. The pressure increases linearly with $P_{\text {in }}$. The slope decreases with increasing channel diameter.

crease of the pressure with the input power. The pressure at a given input power is again higher in narrower channels. For all diameters, the extrapolated pressure at zero input power is nonzero and decreasing with increasing diameter.

\section{B. I- $V$ measurements}

Figure 6 shows in detail the results of $I-V$ measurements on a $\oslash 5 \mathrm{~mm}$ cascaded arc at six different hydrogen gas flow rates $(0.5-3.5 \mathrm{slm})$ and $B=0 \mathrm{~T}$. The operating voltage increases as a function of increasing gas flow rate. It is known from the literature (e.g., Ref. 18) that $\mathrm{H}_{2}$ cascaded arc discharges have a negative slope in their $I-V$ characteristic, which flattens at high current. These results show that in the investigated range of currents and flow rates, the $I-V$ characteristics are almost flat. At the highest flow rates (i.e., pressures), the $I-V$ characteristic still has a negative slope over

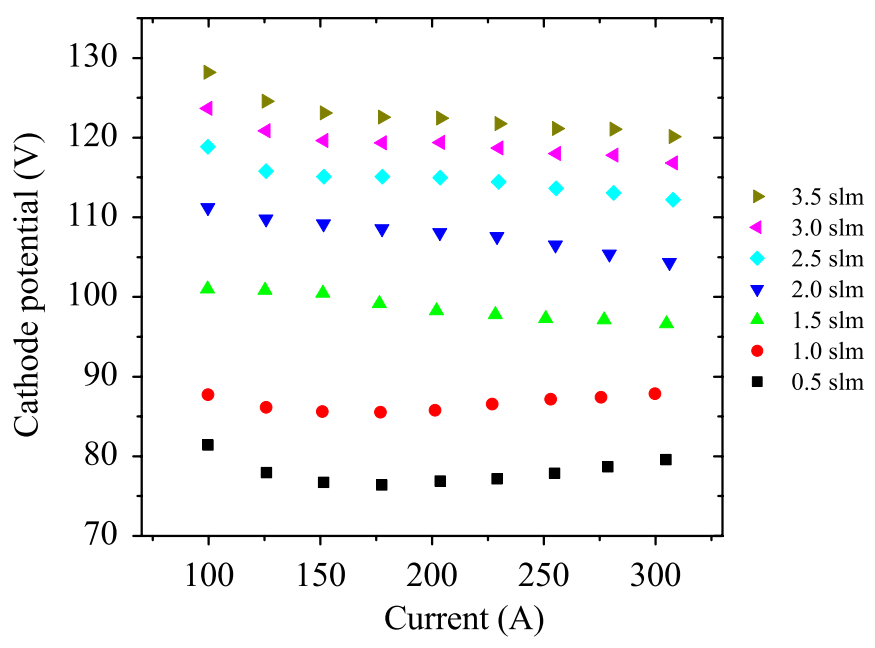

FIG. 6. (Color online) $I-V$ characteristics of a $\oslash 5 \mathrm{~mm}$ cascaded arc at hydrogen gas flow rates between 0.5 and $3.5 \mathrm{slm}$ and $B=0 \mathrm{~T}$. The $I-V$ characteristics have a small negative slope at high gas flow rates and a zero or slightly positive slope at the lowest two gas flow rates.

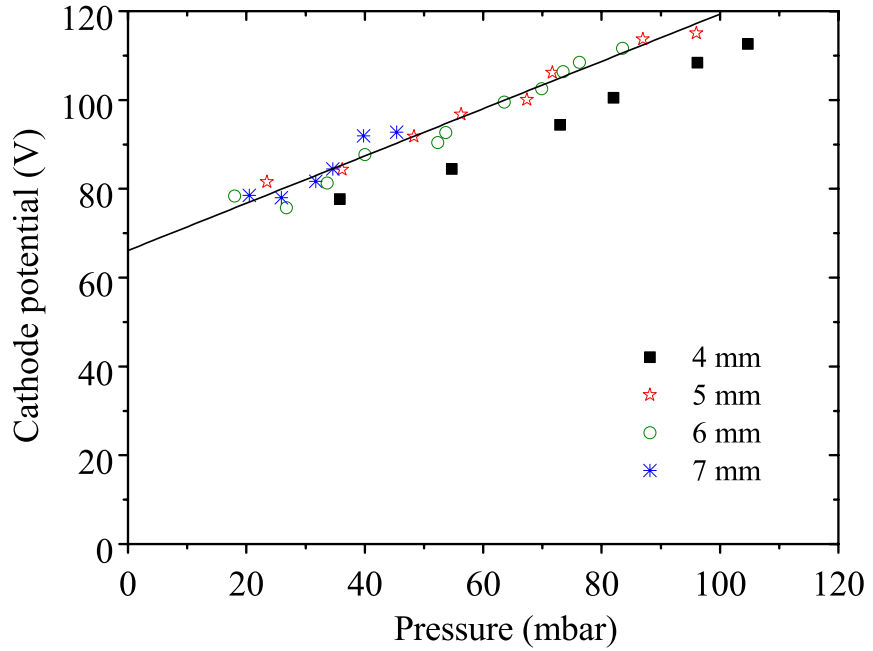

FIG. 7. (Color online) Arc voltage as a function of inlet pressure for channel diameters between 4 and $7 \mathrm{~mm}$. The pressure was varied by changing the hydrogen gas flow rate through the source. The discharge current was $100 \mathrm{~A}$. It is seen that the operating voltage increases linearly with pressure and is independent of the channel diameter.

the whole range of investigated currents. The average slope decreases with decreasing flow rates. At the lowest two flow rates the data even show a shallow minimum, suggesting that the current conduit does not widen in these conditions.

In Fig. 7, the results of cathode voltage measurements are plotted as a function of inlet pressure for channel diameters between 4 and $7 \mathrm{~mm}$. The discharge current was always $100 \mathrm{~A}$. The pressure was varied by changing the hydrogen gas flow rate through the source. We see that for all channel diameters the voltage increases linearly. For $d=5-7 \mathrm{~mm}$, there is no diameter dependence. The operating voltage of the $4 \mathrm{~mm}$ arc is lower than that of the other arcs by about $\sim 10 \%$. In absolute terms, the voltage increases by $50 \%$ as the pressure is increased from 20 to 100 mbar. The black line is a linear fit through the 5,6 , and $7 \mathrm{~mm}$ data.

Figure 8 shows the influence of the inlet pressure on the arc voltage at a higher input power. For these measurements, the arc current was adjusted such that the total input power was constant at $22 \mathrm{~kW}$. Concretely, as the gas flow rate was increased, the current was decreased from $300 \mathrm{~A}$ to about 160 A to compensate for the higher operating voltage. The voltage increased by about $60 \%$ as the pressure increased fourfold. The increase is approximately linear. The slope is the same as the slope in Fig. 7. Due to the negative $I-V$ characteristic in this range of conditions, the absolute voltages are slightly lower.

Figure 9 shows the results of the measurements of the $I-V$ characteristics over the same range of currents, but now at a constant gas flow rate and for channel diameters between 4 and $7 \mathrm{~mm}$. Splines are drawn to guide the eye. These results more clearly show the transition from a $I-V$ characteristic with a negative slope at low currents to one with a zero or positive slope at higher currents. The operating voltage is lower for the larger channels. Comparing the data of the different diameters at, e.g., a current of 100 A, we observe that the slope is zero for small diameters (high pressures) while it is negative for the large diameters (low pressures). 


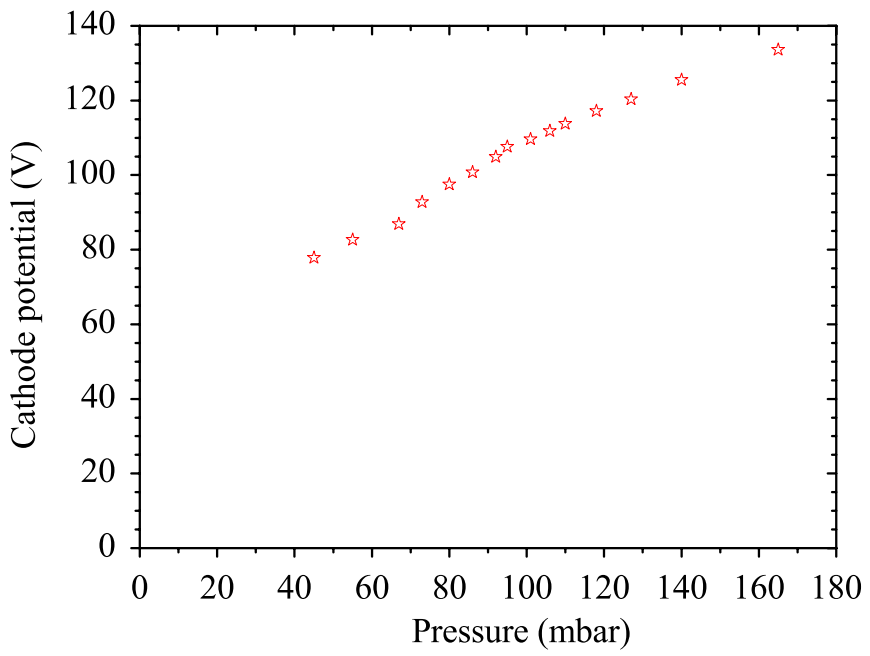

FIG. 8. (Color online) Arc voltage as a function of cathode chamber pressure for a $5 \mathrm{~mm}$ channel diameter. The pressure was varied by changing the hydrogen gas flow rate through the source. As the gas flow rate increased, the arc current was adjusted down, such that the total input power stayed constant at $22 \mathrm{~kW}$. The voltage increased by about $60 \%$ as the pressure increased fourfold.

\section{Thomson scattering measurements}

We measured $n_{e}$ and $T_{e}$ profiles in a scan of the discharge current between 85 and 300 A for each source configuration. Figure 10 shows the profiles obtained for the $\oslash 5 \mathrm{~mm}$ cascaded arc at a gas flow of $3.5 \mathrm{slm}$ and $B$ $=0.2 \mathrm{~T}$. We observe that the peak electron density increases with discharge current, whereas the width and shape of the profile do not change. For the $T_{e}$ profiles, we observe the opposite: The peak temperature increases only slightly from 1.4 to $2.0 \mathrm{eV}$, whereas the width increases strongly. These trends are representative of the trends observed with the other diameters.

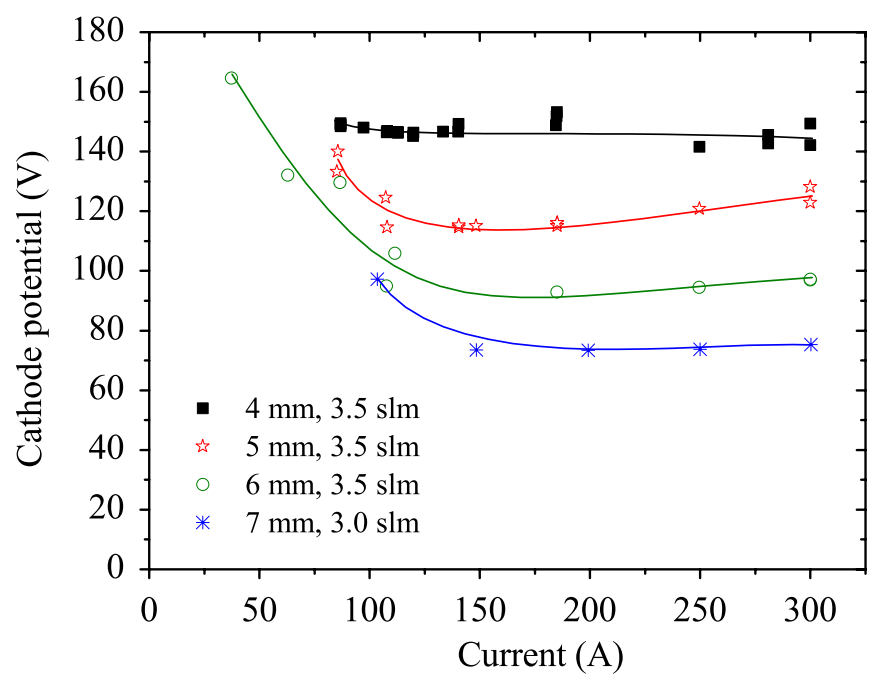

FIG. 9. (Color online) Arc voltage as a function of source current for channel diameters between 4 and $7 \mathrm{~mm}$. Gas flow rate was between 3.0 and $3.5 \mathrm{slm}$. Splines are drawn to guide the eye. The data show that at the same gas flow rate and current, the operating voltage decreases with increasing channel diameter. Furthermore, the slope is negative at low currents and zero above approximately $100 \mathrm{~A}$ of current.

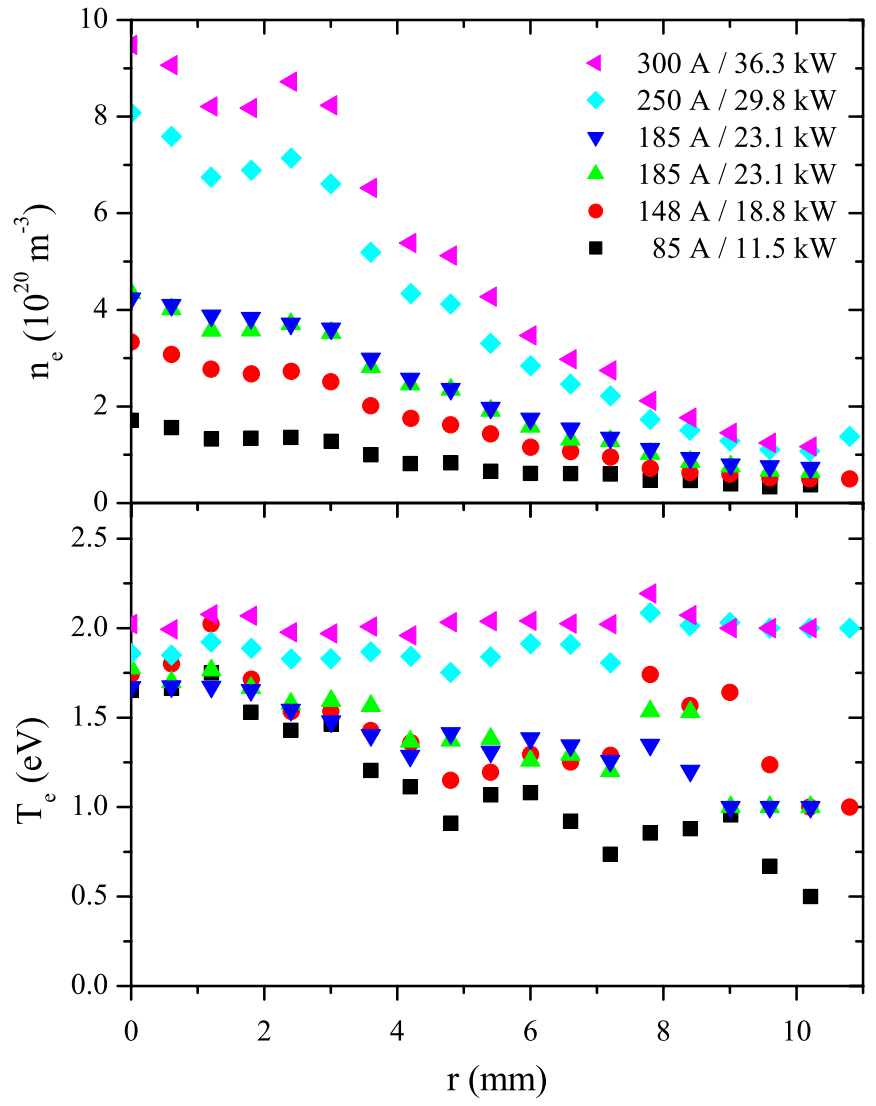

FIG. 10. (Color online) $n_{e}$ and $T_{e}$ profiles measured with Thomson scattering. Operational parameters: $\oslash 5 \mathrm{~mm}, I=300 \mathrm{~A}, B=0.2 \mathrm{~T}, \Phi=3.5 \mathrm{slm}$.

Figure 11 summarizes the results obtained with channel diameters between 4 and $6 \mathrm{~mm}$. The measurements were done at $3.5 \mathrm{slm}$ and $B=0.2 \mathrm{~T}$. The top graph shows the peak density for each channel diameter. We observe that the peak $n_{e}$ is linear with input power for all channel diameters. Extrapolating back to zero density, the minimum input power for sustaining the discharge is approximately $5-10 \mathrm{~kW}$. The densities of the 5 and $6 \mathrm{~mm}$ channels are relatively close together, while that of the $4 \mathrm{~mm}$ arc is significantly lower. The center graph shows that the peak electron temperature increases with increasing input power for $d=4$ and $5 \mathrm{~mm}$ and decreases for $d=6 \mathrm{~mm}$. Furthermore, we observe a clear diameter dependence: $T_{e}$ increases with increasing $d$. The bottom graph indicates that the width of the $n_{e}$ profile is constant and independent of the channel diameter. Only the $\oslash 6 \mathrm{~mm}$ channel has a somewhat larger width at low input power.

All fits of the measured electron density profiles were radially integrated to yield a measure for the total ion flux. In Fig. 12 we have plotted this integrated density divided by the inlet $\mathrm{H}$ atom flux. Multiplying this quantity with the axial velocity yields the gas efficiency of the source (plus eventual extra ionization in the first $4 \mathrm{~cm}$ of the plasma jet due to post-heating). For all diameters, $N / \Gamma_{\mathrm{H}}^{\mathrm{in}}$ increases linearly with input power. There is no dependence on the channel diameter for $d=5,6 \mathrm{~mm}$, but for $d=4 \mathrm{~mm}$ the slope of the integrated density is significantly smaller.

Thomson scattering measurements were also performed 


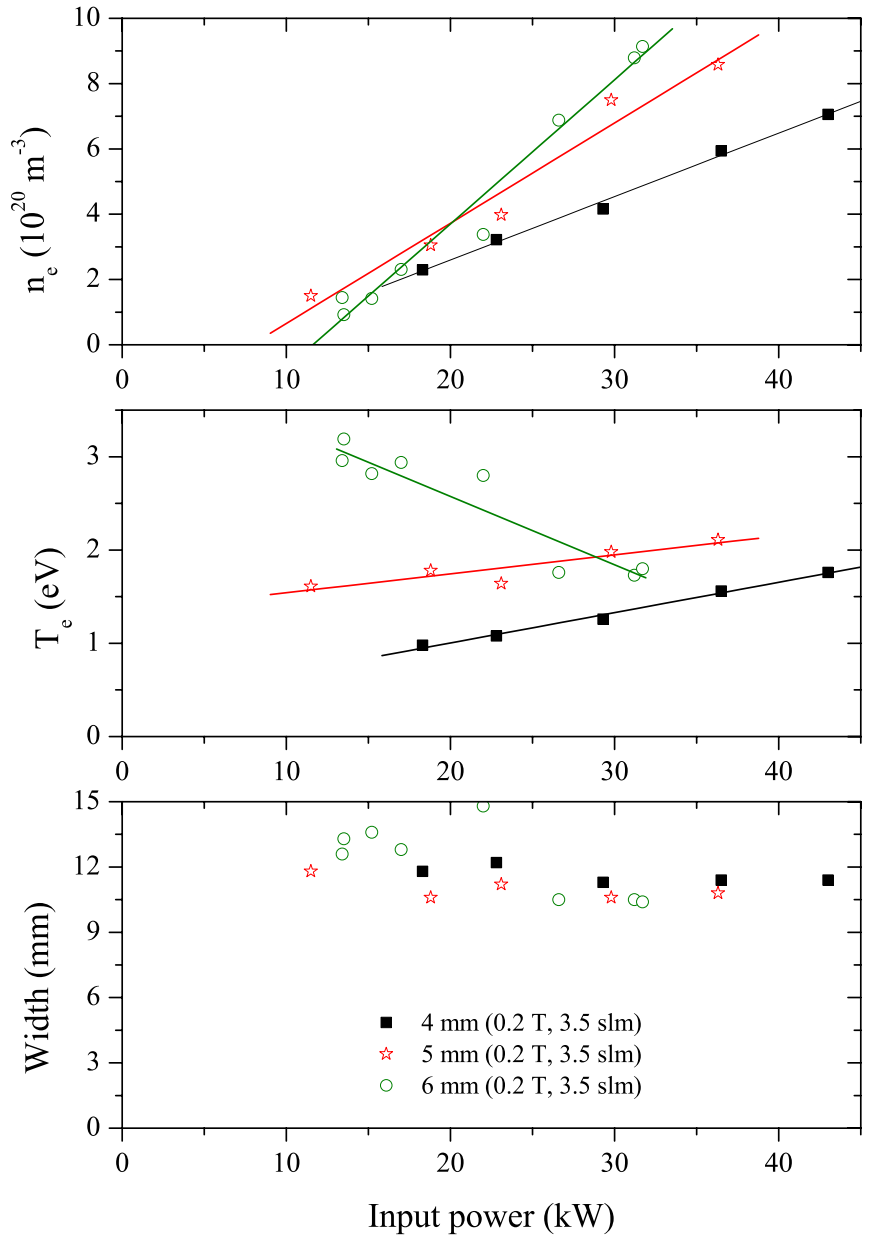

FIG. 11. (Color online) Summary of plasma parameters measured with TS in a scan of the source current and plotted as a function of input power. All values are peak values of the fitted profiles.

as a function of the gas flow rate through the source. These were performed for $d=4-7 \mathrm{~mm}$ at a current of $100 \mathrm{~A}$ and a magnetic field of $0.4 \mathrm{~T}$. The $n_{e}$ profiles measured in the gas flow scan were subjected to the same analysis as above. The integrated densities divided by the inlet $\mathrm{H}$-atom flux are shown as a function of hydrogen gas flow rate in Fig. 13. All channel diameters exhibit a decreasing trend as a function of $\Phi$. There is no dependence on the diameter of the discharge channel. Fitting all these data with a power law gives a dependence of the integrated density on the hydrogen flow rate of $N / \Gamma_{\mathrm{H}}^{\mathrm{in}} \propto \Phi^{-0.65}$.

\section{Measurements of the axial velocity}

The results in Sec. III C cannot be converted into absolute numbers such as the gas efficiency or ion flux without knowing the convective axial velocity of the plasma. The axial velocity was, however, not measured in all conditions. In order to put an estimate of the gas efficiency to the data in Figs. 12 and 13 and to calibrate the estimated gas efficiency from the $I-V$ measurements (see below), we have performed measurements of the axial velocity with OES in one set of operating conditions. In Fig. 14 we have plotted the measured axial velocity as a function of distance from the source exit. These measurements were done with a $4 \mathrm{~mm}$ source at

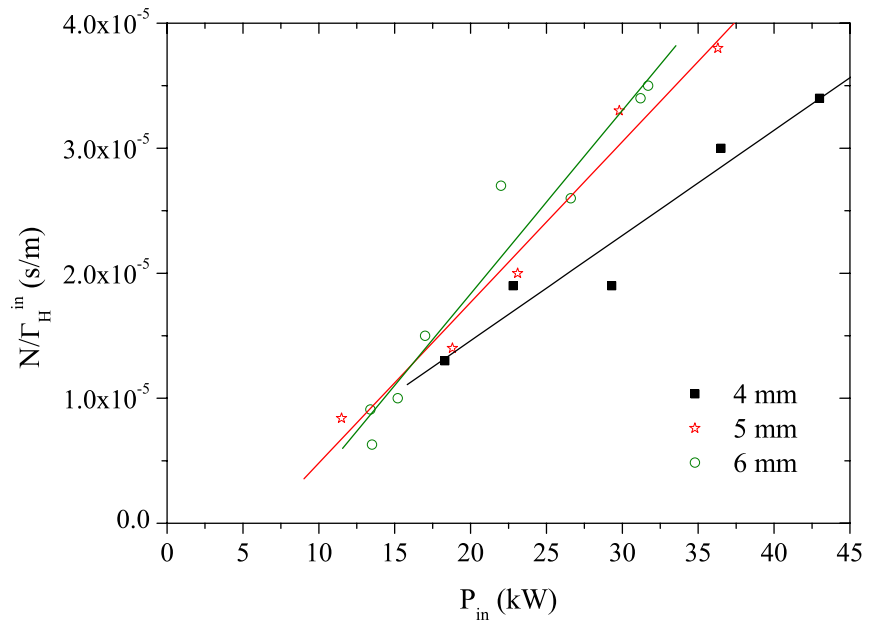

FIG. 12. (Color online) The integrated density divided by the inlet $\mathrm{H}$ atom flux as a function of input power for cascaded arcs with diameters between 4 and $6 \mathrm{~mm}$. Multiplying this quantity with the axial velocity of the plasma yields the gas efficiency. The magnetic field was $0.2 \mathrm{~T}$ and the gas flow rate was in all cases $3.5 \mathrm{slm}$. The increase is linear with the input power. The integrated density is lower for $d=4 \mathrm{~mm}$ than for $d=5,6 \mathrm{~mm}$.

$I=80 \mathrm{~A}, \Phi=2.5 \mathrm{slm}$, and $B=0.4 \mathrm{~T}$. The axial velocity decreases as a function of distance from $\sim 4.5 \mathrm{~km} / \mathrm{s}$ at $z$ $=2 \mathrm{~mm}$ to $\sim 2 \mathrm{~km} / \mathrm{s}$ at $z=9 \mathrm{~cm}$. The TS measurements are done at $z=4 \mathrm{~cm}$. Here, the axial velocity is just over $3 \mathrm{~km} / \mathrm{s}$. As indicated in Sec. II, the measured velocity is a lineaverage over the full width of the plasma beam and several centimeters in the axial direction. Furthermore, most of the light is emitted from the slower edges of the beam. The values given here are expected to be a lower limit.

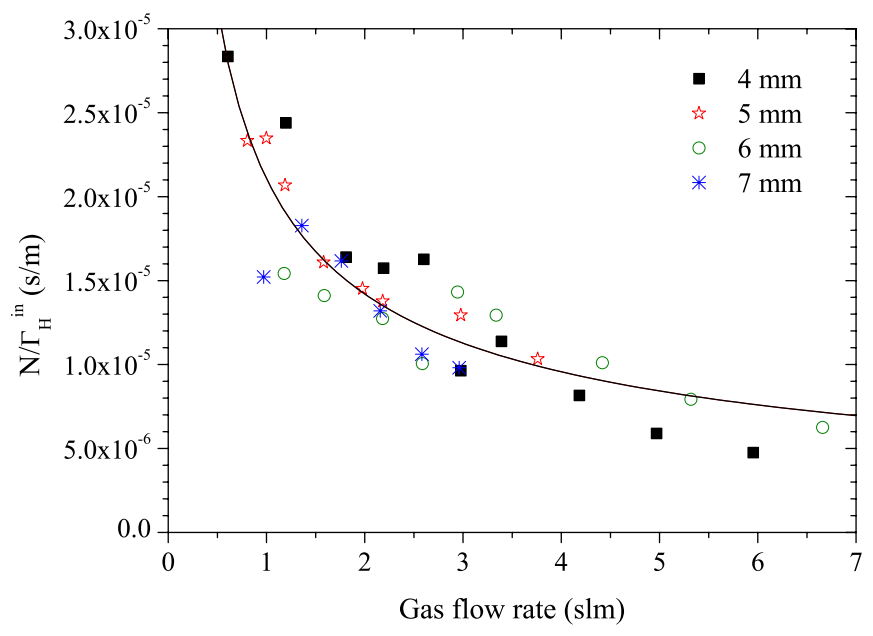

FIG. 13. (Color online) Integrated electron density divided by the inlet $\mathrm{H}$ atom flux as a function of gas flow rate for channel diameters between 4 and $7 \mathrm{~mm}$. The discharge current was $100 \mathrm{~A}$ and the magnetic field $0.4 \mathrm{~T}$. The black line is a power law fit of all data, giving a dependence of $N / \Gamma_{\mathrm{H}}^{\text {in }}$ $\propto \Phi^{-0.65}$. There is no dependence on the channel diameter. 


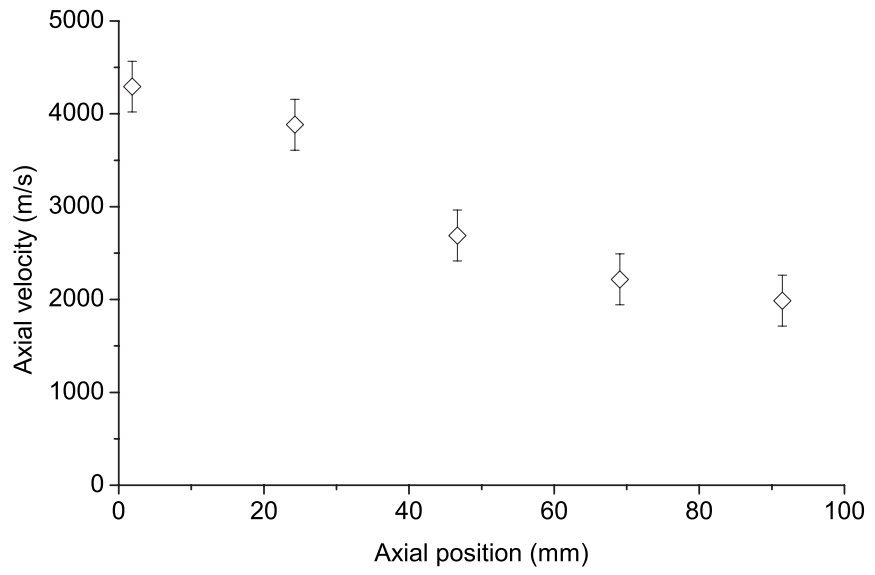

FIG. 14. Axial velocity as a function of distance from the source exit, derived from the Doppler shift of the $\mathrm{H}_{\beta}$ line. Operational conditions were: $d=4 \mathrm{~mm}, I=80 \mathrm{~A}, \Phi=2.5 \mathrm{slm}$, and $B=0.4 \mathrm{~T}$.

\section{ANALYSIS AND INTERPRETATION}

\section{A. Poiseuille flow and estimation of heavy particle temperature from pressure measurements}

Laminar flow of an incompressible fluid through a cylindrical tube is given by ${ }^{19}$

$$
Q=\frac{\pi d^{4} \rho \Delta p}{128 \eta L},
$$

where $Q$ is the mass flow, $d$ is the diameter, $\rho$ the mass density, $\Delta p$ the pressure drop, $\eta$ the dynamic viscosity of the fluid, and $L$ the length of the tube. This is known as Poiseuille flow. A viscous perfect gas flowing isothermally may be considered incompressible over a short section of the tube. For such a gas, we find for an infinitesimally small section

$$
\frac{\mathrm{d} p}{\mathrm{~d} z}=\frac{128 \eta k_{B} T \Gamma}{\pi d^{4} p},
$$

where we have used the definition $Q=m \Gamma$ and the equation of state $\rho=m p / k_{B} T$. If we integrate this over the length of the channel and assume that $p_{\text {out }}^{2}$ is negligible, we calculate that the inlet pressure as a function of gas flow and channel diameter is

$$
p_{\text {in }}=\sqrt{\frac{256 L \eta k_{B} T}{\pi}} \frac{\sqrt{\Gamma}}{d^{2}} .
$$

To test whether we have indeed Poiseuille flow, we have plotted the data from Fig. 4 as a function of $\Gamma^{0.5} d^{-2}$ in Fig. 15. The linear dependence observed in this graph demonstrates that the flow inside the arc channel is compatible with the description of a laminar flow.

As shown in Fig. 5, the pressure is also dependent on the input power in the source. In Fig. 16 we have normalized the measured pressure data from Fig. 5 to $\Gamma^{0.5} d^{-2}$ and plotted the result as a function of input power to see just this effect. Again, we observe a linear dependence, indicating that the effective viscosity varies as a function of input power. Furthermore, there is no dependence of the normalized pressure on the channel diameter.

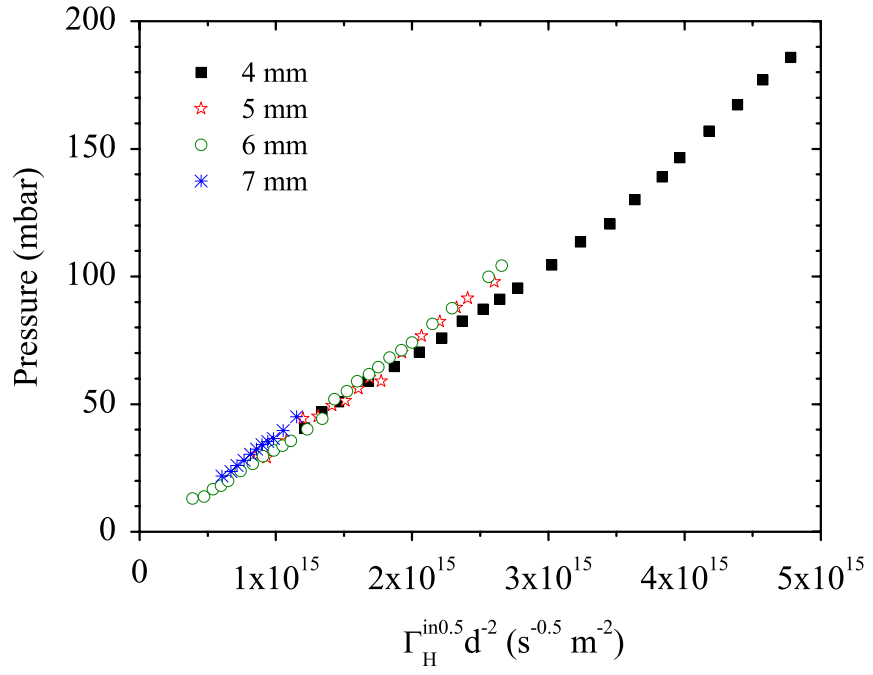

FIG. 15. (Color online) Pressure in the cathode chamber as a function of the square root of the inlet $\mathrm{H}$ flux, normalized to $d^{2}$, for channel diameters between 4 and $7 \mathrm{~mm}$. Data are taken from Fig. 4. For all measurements, the discharge current was $100 \mathrm{~A}$ and the magnetic field $0.4 \mathrm{~T}$. The hydrogen gas flow rate was varied between 0.2 and $10 \mathrm{slm}$.

The effective viscosity is a measure of the average heavy particle temperature in the discharge channel. From Eq. (8) and the measured data, we can calculate the quantity $\eta T$. For the data in Fig. $15, \eta T \approx 0.3-0.4 \mathrm{~kg} \mathrm{~km}^{-1} \mathrm{~s}^{-1}$. Comparing these values to those from literature, ${ }^{20}$ we find that this is compatible with a heavy particle temperature of $T_{h}$ $\approx 0.6-1.0 \mathrm{eV}$.

\section{B. A one parameter model for the cascaded arc efficiency}

As indicated in Sec. I, the input power is deposited into the cascaded arc through Ohmic dissipation in a narrow current conduit. This power is divided between dissociation and ionization of the hydrogen gas, conductive heat losses to the

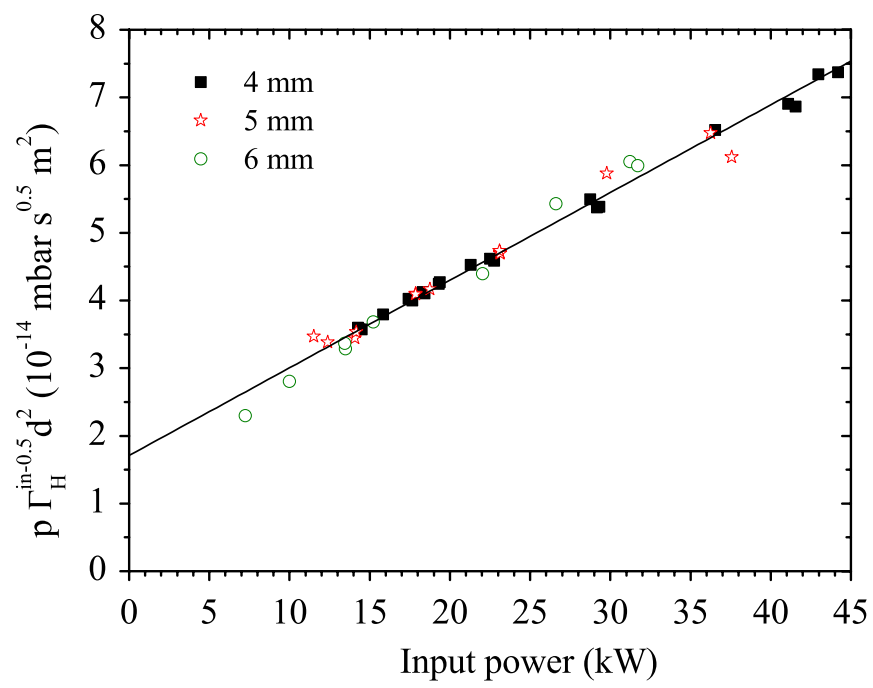

FIG. 16. (Color online) Pressure in the cathode chamber, normalized to the square root of the gas flow and the cross-sectional channel area as a function of the total input power for channel diameters between 4 and $6 \mathrm{~mm}$. Data are taken from Fig. 5. For all measurements, the gas flow rate was $3.5 \mathrm{slm}$, and the magnetic field $0.2 \mathrm{~T}$. 
channel wall, radiation losses from the source and heating of the unionized gas. Based on the $I-V$ data presented in Sec. III and a few simplifying assumptions, we formulate an empirical one parameter model for the cascaded arc operation that allows us to identify the dominant loss mechanism in the discharge channel.

The main assumption we make is that the central temperature is independent of the input power [but via Eq. (2) dependent on the pressure]. The physics basis for this assumption is that the average ionization degree over the volume of the discharge channel is fairly low. Therefore, an increase in temperature leads to a strong increase in ionization degree and hence requires a large amount of energy. Only when the ionization degree approaches $100 \%$ will the temperature significantly increase. In Ref. 21, this has been verified experimentally for a flowing argon arc. If the central temperature is constant, the conductivity equation (1) is constant and hence the arc conductance is only determined by the width and shape of the temperature profile. As we are only interested in global trends, we characterize the profile by a single parameter representing its width and assume a generic profile shape. Since it is not very important for the model what the exact shape is, we choose the simplest possible one: a top-hat with constant temperature out to a radius $r_{\text {eff }}$ and $T_{e}=0$ outside this radius. For convenience, we introduce the filling fraction

$$
\rho=\frac{r_{\mathrm{eff}}}{r_{\mathrm{ch}}},
$$

where $r_{\mathrm{ch}}$ is the radius of the discharge channel. We assume that the velocity profile at the source exit is flat and hence that the ion flux from the source is given by

$$
\Gamma_{\mathrm{H}^{+}}^{\mathrm{out}}=\rho^{2} \alpha \Gamma_{\mathrm{H}}^{\mathrm{in}},
$$

where $\alpha$ is the ionization degree within $r_{\text {eff }}$. The gas efficiency is then by definition equal to $\rho^{2} \alpha$. The only unknown at this point is the ionization degree. This can be estimated from the experimental data, as will be done in the next section.

The filling fraction at which the source operates (and hence the arc conductance) is determined by a balance between the input power and the power losses in the arc. Therefore, we write the input power and possible loss mechanisms as a function of $\rho$. Experimentally, the cascaded arc is operated at constant current. As a function of $\rho$ the total input power becomes

$$
P_{\text {in }}=I^{2} R=\frac{I^{2} L}{\sigma_{\mathrm{pl}} \pi \rho^{2} r_{\mathrm{ch}}^{2}} .
$$

Figure 17 shows the strong $P_{\text {in }} \sim \rho^{-2}$ behavior. Regardless of the exact loss mechanisms, the power losses are likely to increase with the filling fraction. Given a certain current, the arc operates at that $\rho$, where the curve of $P_{\text {in }}$ intersects with that of $P_{\text {loss. }}$. If the current is increased, the whole curve of $P_{\text {in }}$ is raised, leading to a larger filling fraction. In accordance with the assumptions made here, Fig. 10 shows that the central electron temperature measured at $z=4 \mathrm{~cm}$ does not vary much, and that the width of the temperature profile increases

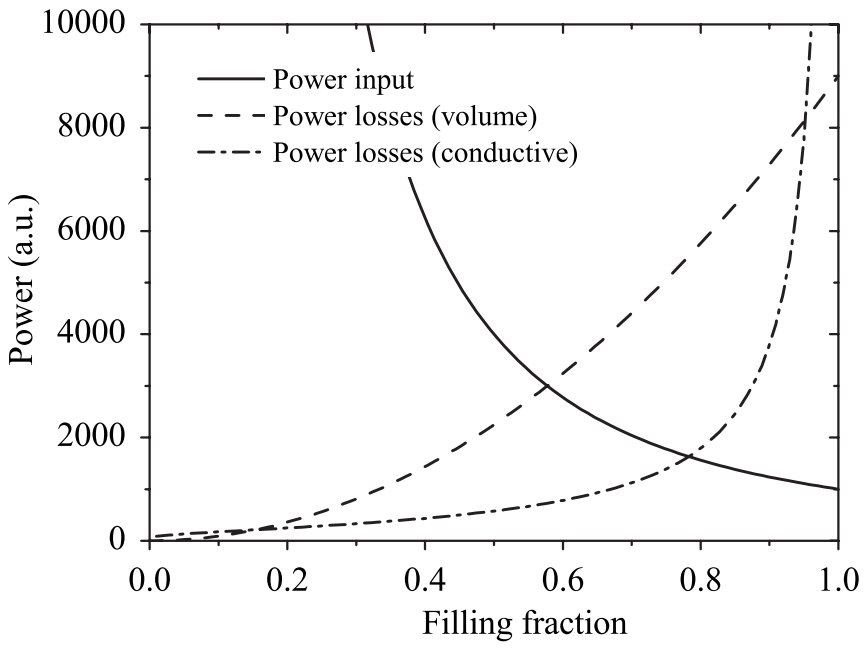

FIG. 17. A qualitative picture showing the stabilization mechanism of the cascaded arc according to the one parameter model. At a given current, the source operates at that filling fraction where the input power (solid line) is equal to the dominant power loss mechanism. Volume losses [dashed line, scaling with $r_{\text {eff }}^{2}$ and conductive losses [dashed-dotted line, scaling with $\left.\ln (\rho)^{-1}\right]$ are indicated.

with input power. We note that this is not a proof of these assumptions, because processes in the first $4 \mathrm{~cm}$ of the plasma beam might have influenced the temperature profile (such as plasma expansion, Ohmic heating, ${ }^{11}$ and viscous ion heating ${ }^{17}$ ).

Figure 17 also explains the stable operation of the cascaded arc: If (e.g., due to a fluctuation) the dissipated power becomes larger than what is required to sustain the discharge, the current channel widens, which in turn immediately lowers $P_{\text {in }}$. Conversely, if the total power falls short, the current channel contracts, forcing the power supplies to operate at a higher voltage and hence increasing the input power again. Figure 17 also shows the dependence on $\rho$ of several possible loss mechanisms. These are:

(1) Volume losses from the hot current conduit, e.g., losses on volume recombination or on radiation from an optically thin medium. These losses scale as

$P_{\text {loss }}^{\mathrm{vol}} \propto \rho^{2} r_{\mathrm{ch}}^{2}$.

We note that these might also be dependent on, e.g., the pressure.

(2) Losses by radial heat conduction to the cooled channel walls through the layer surrounding the current conduit. This scales as

$P_{\text {loss }}^{\text {cond }} \propto \ln (\rho)^{-1}$.

This dependence leads to large losses mainly when $\rho$ approaches unity.

In Sec. IV C we evaluate how $\rho$ scales as a function of $P_{\text {in }}, p$, and $r_{\mathrm{ch}}$ to determine what type of losses are dominant.

To calculate the absolute value of the filling fraction, the average conductivity of the channel is compared to the conductivity of the hot plasma core:

$$
\rho=\sqrt{\frac{\bar{\sigma}}{\sigma_{\mathrm{pl}}}} .
$$




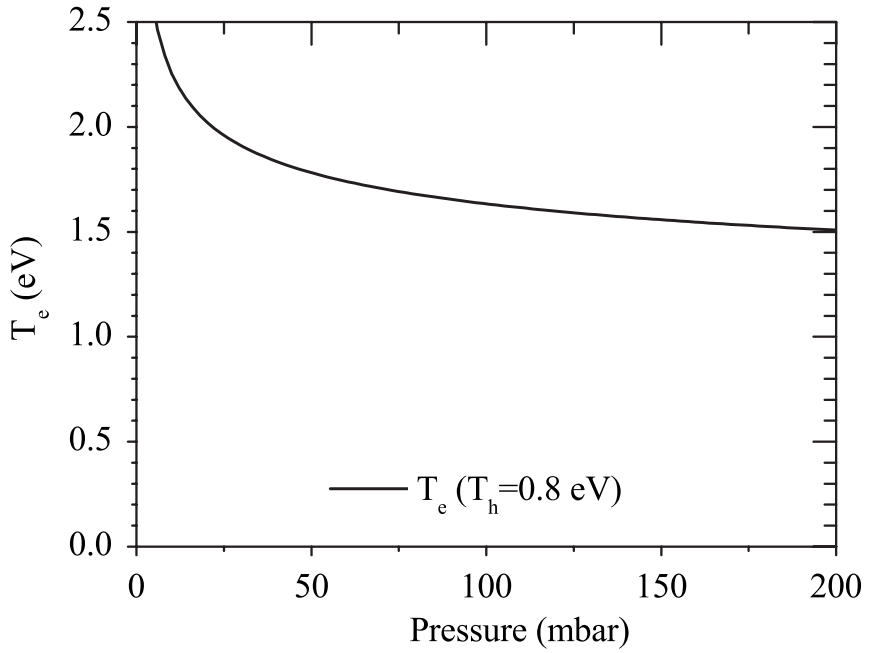

FIG. 18. Temperature as function of the pressure in the discharge channel as calculated from charged particle balance in the source. Heavy particle temperature $T_{h} \approx 0.8 \mathrm{eV}$ is estimated from the viscosity measurements.

The $\sigma_{\mathrm{pl}}$ is dependent the central temperature according to Eq. (1) and this is in turn dependent on the pressure according to Eq. (2). The calculated electron temperature is plotted in Fig. 18 for the range of pressures relevant to our setup. In the range of interest, the temperature varies fairly slowly with pressure. Its value is $\hat{T}_{e} \approx 1.5-2.0 \mathrm{eV}$ in the relevant pressure range, making the conductivity $\sigma_{\mathrm{pl}} \approx 6-9$ $\times 10^{3} \Omega^{-1} \mathrm{~m}^{-1}$. From the measured $I-V$ data and the channel geometry, the filling fraction is calculated with

$$
\rho=\sqrt{\frac{\bar{\sigma}}{\sigma_{\mathrm{pl}}}}=\left(\frac{I L}{\pi r_{\mathrm{ch}}^{2} V \sigma_{\mathrm{pl}}}\right)^{1 / 2} .
$$

\section{Estimation of the plasma production from $I-V$ measurements}

According to the method described in the previous section, we have plotted in Fig. $19 \rho^{2}$ as a function of input power, using the data of Fig. 6. The figure shows a number of interesting aspects. First, for gas flow rates between 1.5 and $3.5 \mathrm{slm}$, the linear fits show that $\rho^{2}$ scales linearly with the input power. From these data (taken with one diameter), we conclude that the dominant loss process inside the arc channel is one scaling with the volume of the current conduit. At the lowest gas flow rates of $\Phi=1.0$ and $0.5 \mathrm{slm}$, the dependence deviates slightly from linear. For these gas flow rates, the lines through the data points are splines drawn by hand. For these $\Phi$, the slope decreases slightly with increasing input power. Second, at a given input power, the current conduit widens as the gas flow rate decreases. This indicates that the power losses (sketched in Fig. 17) become smaller if the pressure in the arc channel decreases. Third, extrapolating back to zero filling of the channel (i.e., source extinction), we see that there is a minimum power of $\sim 3 \mathrm{~kW}$ required to sustain the discharge. This power $P_{0}$ is not dependent on the gas flow rate. Finally, at 0.5 and $1.0 \mathrm{slm}$ and high powers, $\rho$ actually exceeds 1 . By definition, $\rho$ cannot exceed 1, so in these conditions the used model is no

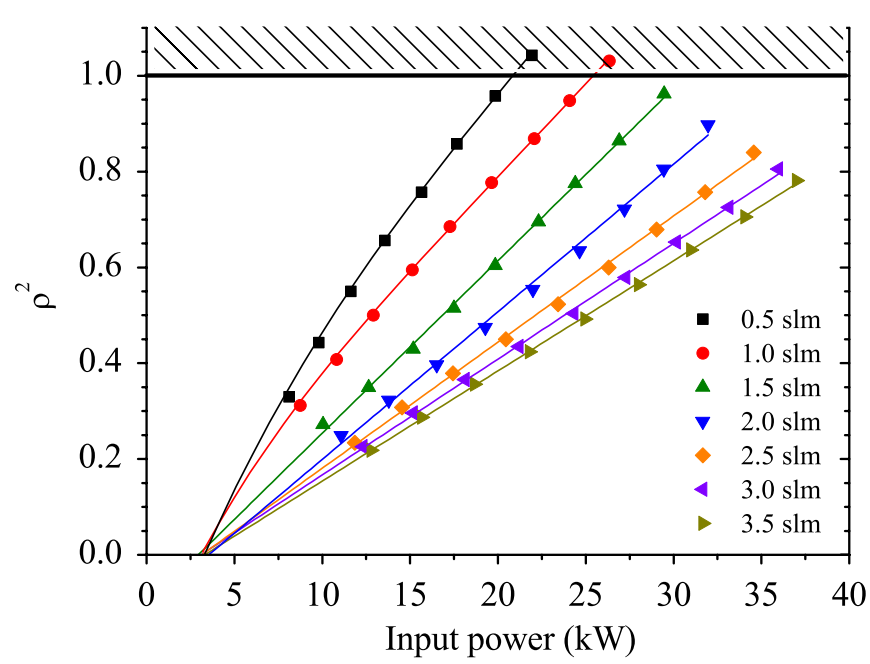

FIG. 19. (Color online) The filling factor squared as a function of the input power. All data obtained with a $\oslash 5 \mathrm{~mm}$ cascaded arc. Data show linear dependence on all but the lowest two gas flow rates. This indicates that volume losses are dominant inside the arc channel. For $\Phi=1.5-3.5 \mathrm{slm}$, the lines are linear fits, for $\Phi=0.5-1.0 \mathrm{slm}$ they are drawn by hand.

longer expected to be valid. Specifically, the assumption of a fixed electron temperature will not hold when $\rho$ approaches 1. In Fig. 6 we observe that in these conditions the $I-V$ characteristic again gets a positive slope, suggesting that the current conduit does not widen any further. Together with $T_{e}$, the ionization degree in the center is expected to rise as $\rho$ approaches 1 .

A possible interpretation for the volume losses being dominant can be found in the fact that the electron temperature is higher than the heavy particle temperature. The electrons, heated Ohmically to $\sim 1.7 \mathrm{eV}$, transfer thermal energy to the heavy particles through (Coulomb) collisions. The power balance described in Sec. IV B concerns the electrons. From this perspective, the transfer of thermal energy to the heavy particles is considered a power loss. The conductive losses in the radial direction are determined by the radial temperature profile of the heavy particles. Despite the relatively large thermal conductivity of hydrogen, ${ }^{20}$ these losses are apparently not dominant in this range of conditions. This interpretation is consistent with the observation that the filling of the channel becomes larger at lower pressures. At lower pressures/densities, less atoms and ions are present to transfer the thermal energy to.

To estimate the ionization degree to be used in Eq. (10), we calculate the total ion flux from the TS and OES results. The only set of conditions for which the axial velocity was measured is $d=4 \mathrm{~mm}, \Phi=2.5 \mathrm{slm}, I=100 \mathrm{~A}$, and $B=0.4 \mathrm{~T}$, leading to an input power of $P_{\text {in }}=12.5 \mathrm{~kW}$. From Fig. 12, we see that at this input power, $N / \Gamma_{\mathrm{H}}^{\mathrm{in}}=8 \times 10^{-6} \mathrm{~s} / \mathrm{m}$. Multiplying this with $v_{z}=3 \mathrm{~km} / \mathrm{s}$ gives a gas efficiency of $2.5 \%$ and a total ion flux of $\Gamma_{\mathrm{H}^{+}}^{\text {out }}=6 \cdot 10^{19} \mathrm{~s}^{-1}$. From Fig. 19 we see that in these conditions $\rho^{2}=0.25$. Given the known inlet gas flux, we find from Eq. (10) that the ionization degree in the center is 0.1. To compare Fig. 12 with Fig. 19, an assumption has to be made on the scaling of the plasma velocity at the TS location. As it is expected that the plasma exits the source at sound speed $c_{s}$ (Ref. 22) (which depends only on $T_{e}$ ), the 


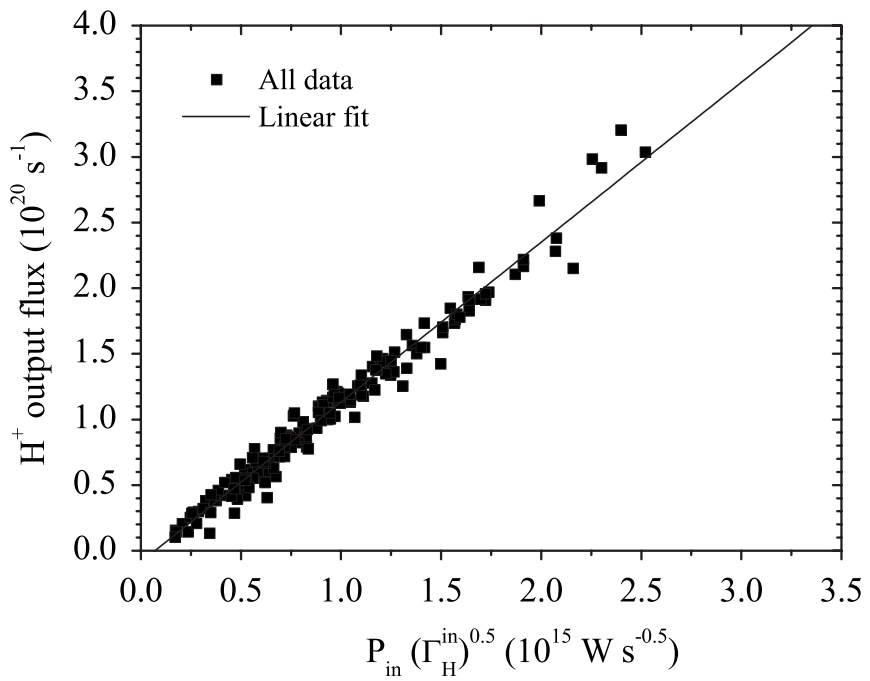

FIG. 20. The flux as calculated from the $I-V$ data of Figs. 6, 7, and 9 as a function of $P_{\mathrm{in}} \cdot \sqrt{\Gamma_{\mathrm{H}}^{\mathrm{in}}}$, showing a clear linear dependence.

velocity at the source exit is independent of $P$. Assuming that the decrease in velocity between the source exit and $z$ $=4 \mathrm{~cm}$ is always approximately the same, the velocity at the TS location will not differ largely from the measured value. Consequently, Fig. 12 implies that the ion flux is linearly dependent on the input power. Given that under these assumptions, both $\Gamma_{\mathrm{H}^{+}}^{\mathrm{out}}$ and $\rho^{2}$ are linearly dependent on $P_{\mathrm{in}}$, the ionization degree must be independent of $P_{\text {in }}$. We will therefore use a constant value of 0.1 for $\alpha$.

In Fig. 20 we have plotted the flux as calculated from the data in Figs. $6-8$ as a function of $P_{\text {in }} \sqrt{\Gamma_{\mathrm{H}}^{\text {in }}}$. The black line is a linear fit of all data. From this figure, we conclude:

(1) The ion flux from a hydrogen cascaded arc in the investigated range of conditions scales as

$\Gamma_{\mathrm{H}^{+}}^{\text {out }}=1.2 \times 10^{5}\left(P_{\mathrm{in}} \sqrt{\Gamma_{\mathrm{H}}^{\mathrm{in}}}\right)-9 \times 10^{18}$.

(2) At a given input power and gas flow rate, the plasma production is independent of the channel diameter.

(3) The gas efficiency $\gamma=\Gamma_{\mathrm{H}^{+}}^{\text {out }} / \Gamma_{\mathrm{H}}^{\mathrm{in}}$ scales as

$$
\gamma \propto P_{\text {in }}\left(\Gamma_{\mathrm{H}}^{\mathrm{in}}\right)^{-0.5} .
$$

The second conclusion implies that if at a given input power and gas flow rate the channel diameter is increased, the filling fraction will in fact not change [see Eq. (10)]. This means that the volume $\pi r_{\text {eff }}^{2} L$ increases with $d^{2}$. At the same time, according to Eq. (8), the pressure decreases with $d^{-2}$. The total number of particles in the current conduit thus remains the same. Consistent with the interpretation given above, this number of particles sets the power loss. The third conclusion is in reasonable agreement with the TS results of Fig. 13 that showed a dependence on the gas flow rate of $\Phi^{-0.65}$.

The dependence of the ion flux on the square root of the flow rate is confirmed by the results in Fig. 21, where the ion flux at constant input power is plotted as a function of gas flow rate for the data presented in Fig. 8. The input power was kept constant by adjusting the source current to the volt-

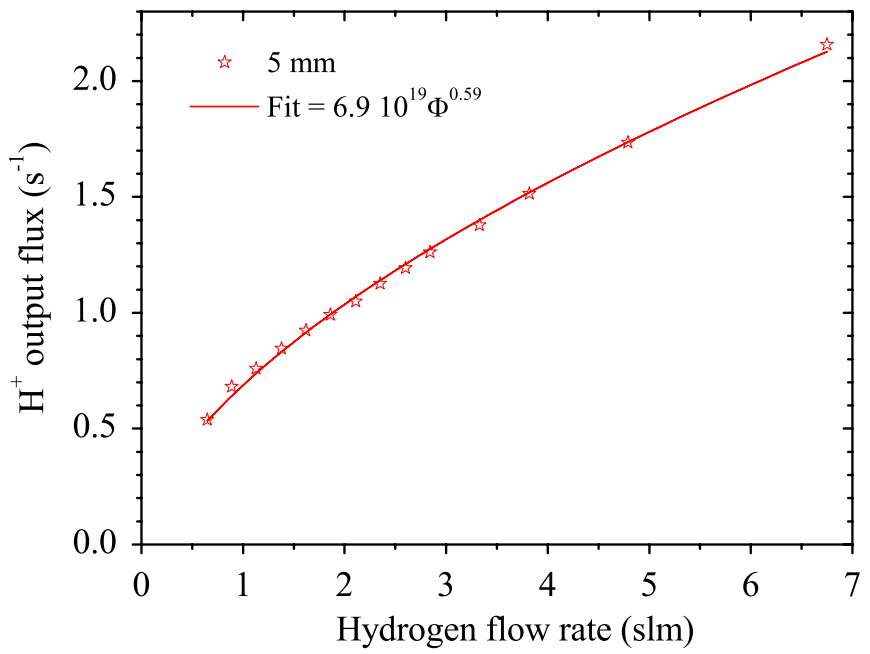

FIG. 21. (Color online) The plasma production (determined from the $I-V$ data) at a constant input power plotted as a function of the hydrogen flow rate. The channel diameter was $5 \mathrm{~mm}$ and the input power was $22 \mathrm{~kW}$.

age change due to the increased pressure. The data were fitted with a power law, giving a dependence of $\Gamma_{\mathrm{H}^{+}}^{\text {out }} \Phi^{0.59}$, which is close to 0.5 .

\section{DISCUSSION}

\section{A. Comparison between arc measurements and measurements downstream}

In this work, the magnetic field during the TS and OES measurements was kept below $0.4 \mathrm{~T}$ to minimize extra power dissipation and plasma production in the nozzle region by the mechanism described in Ref. 11. Even at this value of the magnetic field, however, the effect is not negligible. Due to the extended current path, the discharge voltage at a given current (and hence the input power) increases when the magnetic field is switched on. To estimate the degree to which the power deposition is determined by nozzle effects, we compare the input power during the magnetic field pulse to that at $B=0 \mathrm{~T}$. Dividing the difference between these two by the input power during the field pulse shows that at $0.4 \mathrm{~T}$ and nozzle diameters about $2 \mathrm{~mm}$ larger than the channel, about $25 \%$ of the input power is dissipated in the nozzle region outside the source channel. This number does not depend strongly on the exact experimental conditions. To what extend this extra power dissipation influences the plasma production will be the subject of future work. However, extrapolating the results in Fig. 4 of Ref. 11 back to zero $B$-field suggests that the difference in plasma production between $B=0.4 \mathrm{~T}$ and $B=0 \mathrm{~T}$ is also of the order of $25 \%$.

This effect, together with viscous ion heating, ${ }^{17}$ molecular assisted recombination, ${ }^{8,9}$ and not having velocity data for all experimental conditions introduces some uncertainties in the comparison between the estimated fluxes from the $I-V$ measurements and the results in Figs. 12 and 13. However, the trends predicted by the $I-V$ measurements are well reproduced by the TS measurements. Furthermore, the main con- 


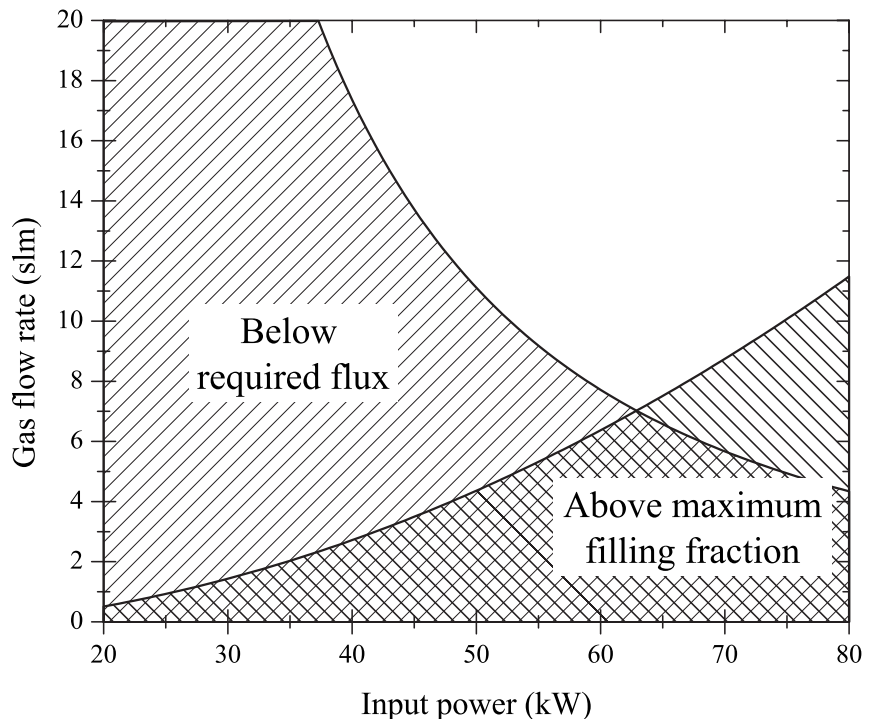

FIG. 22. Determination of the operational range for a high power cascaded arc. The curve with negative slope is determined from the minimum required flux for the Magnum-PSI experiment. The other curve is determined from the condition $\rho \leqslant 0.9$.

clusions are based on the scaling that results from the analysis of the $I-V$ data, which does not depend on these uncertainties.

\section{B. Extrapolation to larger sources}

As explained in Sec. I, we need to improve the output flux by a factor of 10 relative to $P_{\text {in }}=12 \mathrm{~kW}$ and $\Phi$ $=2.5 \mathrm{slm}$ to a total flux of $6 \times 10^{20} \mathrm{~s}^{-1}$. Extrapolating the results of Fig. 20 to this flux gives the condition

$$
P_{\text {in }} \sqrt{\Gamma_{\mathrm{H}}^{\text {in }}} \geqslant 5 \cdot 10^{15} \mathrm{~W} \mathrm{~s}^{-1 / 2} .
$$

The operational parameters for which this condition is not met are indicated by the left shaded area in Fig. 22. The minimum required gas flow rate decreases quadratically as a function of the input power.

Another issue to consider is that the model is not expected to remain valid as the filling fraction $\rho$ approaches unity. Using Eq. (10), the scaling of the ion flux found in Eq. (16) is turned into an expression for $\rho$. Taking $\rho=0.9$ as the maximum filling fraction for which our analysis is to hold, an equation in $P_{\text {in }}$ and $\Gamma_{\mathrm{H}}^{\mathrm{in}}$ is formulated. The solution of this equation is also plotted in Fig. 22. The shaded area at low gas flow rates and high input powers, indicates where the model will not hold. Optimizing to a minimal gas flow rate, Fig. 22 shows that the flux requirement can be met with an input power of $65 \mathrm{~kW}$ and a gas flow rate of $7 \mathrm{slm}$.

One more important factor in scaling to higher powers is the heat load on the channel walls. Numerical analysis of the thermal stresses in the cascade plates show that with sufficient cooling of the plates, the maximum power load on the walls is $Q_{\max } \approx 10 \mathrm{MW} / \mathrm{m}^{2}$. Assuming that most of the input power goes to the channel wall (surface area $S_{\text {wall }}$ ), the wall load is estimated with

$$
Q_{\text {wall }}=\frac{P_{\text {in }}}{S_{\text {wall }}}=\frac{P_{\text {in }}}{2 \pi r_{\mathrm{ch}} L} .
$$

The maximum wall load $Q_{\max }$ now sets the minimum channel radius at a given input power. Using a source with the same length-to-radius ratio as the current sources, i.e., $L$ $\approx 10 r_{\mathrm{ch}}$, the minimum diameter becomes

$$
r_{\min }=\sqrt{\frac{P_{\text {in }}}{20 \pi Q_{\max }}} .
$$

At $P_{\text {in }}=65 \mathrm{~kW}$, the minimal radius of the source is $1 \mathrm{~cm}$.

Without magnetic field, the gas efficiency will according to the scaling equation (17) be $\sim 9 \%$. To calculate the energy efficiency, we take for the average energy per electron-ion pair

$$
E=\frac{1}{2} E_{\mathrm{diss}}+E_{\mathrm{ion}}+\frac{1}{2} m_{i} v_{a}^{2}+\frac{5}{2} k_{B}\left[T_{e}+T_{i}\right] \approx\left[16+5 \hat{T}_{e}\right] \mathrm{eV},
$$

where we have assumed for this approximation $T_{i}=T_{e} . E_{\mathrm{diss}}$ $=4.5 \mathrm{eV}$ is the dissociation energy of a $\mathrm{H}_{2}$ molecule and $E_{\text {ion }}=13.6 \mathrm{eV}$ is the ionization energy of atomic hydrogen. Taking $\hat{T}_{e} \approx 2 \mathrm{eV}$, the total power in the plasma beam is $\Gamma_{\mathrm{H}^{+}}^{\text {out }} E \approx 2.5 \mathrm{~kW}$. At $P_{\text {in }}=65 \mathrm{~kW}$, this implies an energy efficiency of $4 \%$.

\section{SUMMARY AND CONCLUSIONS}

Cascaded arc plasma sources with discharge channel diameters between 4 and $7 \mathrm{~mm}$ were experimentally investigated as a function of the operational parameters. Pressure measurements showed that the flow through the channel is consistent with laminar flow. Thomson scattering measurements showed the electron density at $4 \mathrm{~cm}$ from the source exit increasing linearly with input power. The measured $I-V$ characteristics were analyzed in terms of a model with the effective filling of the discharge channel as the most important parameter. The main assumption that went into the model is that the electron temperature in the center of the discharge channel depends on the pressure, but not on the input power. This analysis showed that the dominant power loss mechanism inside the source is one that scales with the effective volume of the plasma in the discharge channel. The ion flux was estimated from the filling fraction by $\rho^{2} \alpha \Gamma_{\mathrm{H}}^{\mathrm{in}}$. The ionization degree in the center of the channel $\alpha$ was determined from a comparison between the $I-V$ data and the estimated absolute flux from TS and OES measurements and assumed to be constant. This analysis showed that the ion flux scales with the operational parameters as $P_{\text {in }}\left(\Gamma_{\mathrm{H}}^{\mathrm{in}}\right)^{0.5}$ and the gas efficiency as $P_{\text {in }}\left(\Gamma_{\mathrm{H}}^{\mathrm{in}}\right)^{-0.5}$. Given an input power and gas flow rate, the plasma production is independent of the channel diameter. Extrapolation of the data showed that a tenfold increase in flux is possible with a $2 \mathrm{~cm}$ diameter source at $65 \mathrm{~kW}$ input power, leading to an estimated gas efficiency of $9 \%$ and an energy efficiency of $4 \%$. Future work will include the verification of the predicted fluxes at higher input powers with a combination of TS measurements, a better determination of the axial velocity and ion saturation current measurements. 


\section{ACKNOWLEDGMENTS}

The authors acknowledge the skillful technical assistance of R. S. Al and B. de Groot during the experiments. We would furthermore like to thank H. de Blank, A. W. Kleyn, W. R. Koppers, and J. Rapp for useful discussions.

This work, supported by the European Communities under the Contract of Association between EURATOM/FOM, was carried out within the framework of the European Fusion Programme with financial support from NWO and the research school CPS. The views and opinions expressed herein do not necessarily reflect those of the European Commission.

${ }^{1}$ H. Maecker, Z. Naturforsch. A 11A, 457 (1956).

${ }^{2}$ A. J. M. Buuron, M. C. M. van de Sanden, W. J. van Ooij, R. M. A. Driessens, and D. C. Schram, J. Appl. Phys. 78, 528 (1995).

${ }^{3}$ R. A. B. Zijlmans, J. H. van Helden, D. C. Schram, and R. Engeln, in Light Sources 2004: Proceedings of the Tenth International Symposium on the Science and Technology of Light Sources, Toulouse, 18-22 July 2004, edited by G. Zissis (CRC, Boca Raton, FL, 2004), Vol. 182, pp. 355-356.

${ }^{4}$ M. Winter, C. Boie, M. Auweter-Kurtz, and L. H. Kurtz, Proceedings of the Conference, 2nd European Spacecraft Propulsion Conference, Noordwijk, 1997, edited by M. Perry (European Space Agency, Paris, 1997), ESA SP-398, p. 431.

${ }^{5}$ M. Shimada, D. J. Campbell, V. Mukhovatov, M. Fujiwara, N. Kirneva, K. Lackner, M. Nagami, V. D. Pustovitov, N. Uckan, J. Wesley, N. Asakura, A. E. Costley, A. J. H. Donné, E. J. Doyle, A. Fasoli, C. Gormezano, Y. Gribov, O. Gruber, T. C. Hender, W. Houlberg, S. Ide, Y. Kamada, A. Leonard, B. Lipschultz, A. Loarte, K. Miyamoto, V. Mukhovatov, T. H. Osborne, A. Polevoi, and A. C. C. Sips, Nucl. Fusion 47, S1 (2007).

${ }^{6}$ G. Federici, P. Andrew, P. Barabaschi, J. Brooks, R. Doerner, A. Geier, A. Herrmann, G. Janeschitz, K. Krieger, A. Kukushkin, A. Loarte, R. Neu, G. Saibene, M. Shimada, G. Strohmayer, and M. Sugihara, J. Nucl. Mater. 313-316, 11 (2003).

${ }^{7}$ J. Westerhout, W. R. Koppers, W. A. J. Vijvers, R. S. Al, S. Brezinsek, S.
Brons, H. J. N. van Eck, R. Engeln, B. de Groot, R. Koch, H. J. van der Meiden, M. P. Nuijten, V. Philipps, M. J. van de Pol, P. R. Prins, U. Samm, J. Scholten, D. C. Schram, B. Schweer, P. H. M. Smeets, D. G. Whyte, E. Zoethout, A. W. Kleyn, W. J. Goedheer, N. J. Lopes Cardozo, and G. J. van Rooij, Phys. Scr., T 128, 18 (2007).

${ }^{8}$ M. J. de Graaf, Phys. Rev. E 48, 2098 (1993).

${ }^{9}$ N. Ohno, N. Ezumi, S. Takamura, S. I. Krasheninnikov, and A. Yu. Pigarov, Phys. Rev. Lett. 81, 818 (1998).

${ }^{10}$ G. M. W. Kroesen, D. C. Schram, and J. C. M. de Haas, Plasma Chem. Plasma Process. 10, 531 (1990).

${ }^{11}$ G. J. van Rooij, V. P. Veremiyenko, W. J. Goedheer, B. de Groot, A. W. Kleyn, P. H. M. Smeets, T. W. Versloot, D. G. Whyte, R. Engeln, D. C. Schram, and N. J. Lopes Cardozo, Appl. Phys. Lett. 90, 121501 (2007).

${ }^{12}$ R. P. Dahiya, M. J. de Graaf, R. J. Severens, H. Swelsen, M. C. M. van de Sanden, and D. C. Schram, Phys. Plasmas 1, 2086 (1994).

${ }^{13}$ Z. Qing, Ph.D. thesis, Eindhoven University of Technology, 1995.

${ }^{14}$ L. Spitzer, Physics of Fully Ionized Gases (Interscience, London, 1956).

${ }^{15}$ D. C. Schram, S. Mazouffre, R. Engeln, and M. C. M. van de Sanden, Atomic and Molecular Beams, edited by R. Campargue (Springer, New York, 2001), p. 209.

${ }^{16}$ H. J. van der Meiden, R. S. Al, C. J. Barth, A. J. H. Donné, R. Engeln, W. J. Goedheer, B. de Groot, A. W. Kleyn, W. R. Koppers, N. J. Lopes Cardozo, M. J. van de Pol, P. R. Prins, D. C. Schram, A. E. Shumack, P. H. M. Smeets, W. A. J. Vijvers, J. Westerhout, G. M. Wright, and G. J. van Rooij, Rev. Sci. Instrum. 79, 013505 (2008).

${ }^{17}$ A. E. Shumack, V. P. Veremiyenko, D. C. Schram, H. J. van der Meiden, W. A. J. Vijvers, J. Westerhout, N. J. Lopes Cardozo, and G. J. van Rooij, "Rotation of a strongly magnetized hydrogen plasma column determined from a two distribution asymmetric Balmer $\beta$ spectral line," Phys. Rev. E (submitted).

${ }^{18}$ K. Behringer and N. van Cung, Appl. Phys. 22, 373 (1980).

${ }^{19}$ L. D. Landau and E. M. Lifshitz, Fluid Mechanics, 2nd ed. (Pergamon, Oxford, 1987).

${ }^{20}$ A. B. Murphy, Plasma Chem. Plasma Process. 20, 279 (2000).

${ }^{21}$ J. J. Beulens, M. J. de Graaf, and D. C. Schram, Plasma Sources Sci. Technol. 2180 (1993).

${ }^{22}$ P. H. Oosthuizen and W. E. Carscallen, Compressible Fluid Flow (McGraw-Hill, New York, 1997). 